OPEN ACCESS

Edited by:

Rita Verhelst,

Ghent University, Belgium

Reviewed by:

Claudio De Lucia,

University of Naples Federico II, Italy

Greg Gloor,

University of Western Ontario, Canada

Caroline Mitchell,

Massachusetts General Hospital, USA

*Correspondence:

Sarah Lebeer,

Department of Bioscience

Engineering, University of Antwerp,

Groenenborgerlaan 171

Antwerp B-2020, Belgium

sarah.lebeer@uantwerpen.be

${ }^{t}$ These authors have contributed equally to this work.

Specialty section:

This article was submitted to Clinical and Translational Physiology, a section of the journal Frontiers in Physiology

Received: 09 December 2014 Accepted: 02 March 2015 Published: 25 March 2015

Citation:

Petrova MI, Lievens E, Malik S, Imholz $N$ and Lebeer $S$ (2015) Lactobacillus species as biomarkers and agents that can promote various aspects of vaginal health. Front. Physiol. 6:81. doi: 10.3389/fphys.2015.00081

\section{Lactobacillus species as biomarkers and agents that can promote various aspects of vaginal health}

\author{
Mariya I. Petrova ${ }^{1,2+}$, Elke Lievens ${ }^{1,2 \dagger}$, Shweta Malik ${ }^{1,2 \dagger}$, Nicole Imholz ${ }^{1,2}$ and \\ Sarah Lebeer ${ }^{1,2 *}$ \\ ${ }^{1}$ Department of Bioscience Engineering, University of Antwerp, Antwerp, Belgium, ${ }^{2}$ Centre of Microbial and Plant Genetics, \\ KU Leuven, Leuven, Belgium
}

The human body is colonized by a vast number of microorganisms collectively referred to as the human microbiota. One of the main microbiota body sites is the female genital tract, commonly dominated by Lactobacillus spp., in approximately $70 \%$ of women. Each individual species can constitute approximately 99\% of the ribotypes observed in any individual woman. The most frequently isolated species are Lactobacillus crispatus, Lactobacillus gasseri, Lactobacillus jensenii and Lactobacillus iners. Residing at the port of entry of bacterial and viral pathogens, the vaginal Lactobacillus species can create a barrier against pathogen invasion since mainly products of their metabolism secreted in the cervicovaginal fluid can play an important role in the inhibition of bacterial and viral infections. Therefore, a Lactobacillus-dominated microbiota appears to be a good biomarker for a healthy vaginal ecosystem. This balance can be rapidly altered during processes such as menstruation, sexual activity, pregnancy and various infections. An abnormal vaginal microbiota is characterized by an increased diversity of microbial species, leading to a condition known as bacterial vaginosis. Information on the vaginal microbiota can be gathered from the analysis of cervicovaginal fluid, by using the Nugent scoring or the Amsel's criteria, or at the molecular level by investigating the number and type of Lactobacillus species. However, when translating this to the clinical setting, it should be noted that the absence of a Lactobacillus-dominated microbiota does not appear to directly imply a diseased condition or dysbiosis. Nevertheless, the widely documented beneficial role of vaginal Lactobacillus species demonstrates the potential of data on the composition and activity of lactobacilli as biomarkers for vaginal health. The substantiation and further validation of such biomarkers will allow the design of better targeted probiotic strategies.

Keywords: vaginal microbiota, lactobacilli, bacterial vaginosis, STIs, probiotics

\section{Introduction}

Understanding the link between the microbiota and our health is the focus of a growing number of research projects and papers, with new insights becoming available every day. The Human Microbiome Project and the European MetaHIT consortium initiated almost one decade ago, aim at detailed characterization of the structure and the composition of the microbiota from various body 
sites. Primary attention has been focused on the composition and function of the gastrointestinal (GI) microbiota and its relation with health and disease. Nevertheless, in recent years, the microbiota from other body sites, such as the skin, oronasopharyngeal cavity and genital tract, have also gained more attention. An important body site providing a habitat for the development of structured microbial communities is the vaginal tract, which is broadly colonized by microorganisms known as the vaginal microbiota (VMB). Residing at the port of entry of various pathogens causing urogenital and sexually transmitted infections (STIs) in women, there has been an increasing interest in the composition and function of the VMB. Therefore, the VMB has been recognized as an important factor involved in the protection of the host from various bacterial, fungal and viral pathogens. In addition, the VMB of the mother plays an essential role in the initial colonization of new-born babies and therefore the development of a healthy GI and skin microbiota (Dominguez-Bello et al., 2010). It is recognized for a long time that the healthy VMB (which generally refers to lack of symptoms, absence of various infections, and good pregnancy outcome) is dominated mainly by Lactobacillus species, of which the presence can be therefore used as a valuable biomarker for evaluating health and disease. However, it is only now since the more wide-spread application of high throughput sequencing approaches possible to provide a balanced insight and perspective on their multifaceted appearance in the VMB and their multifaceted role in vaginal health.

\section{Lactobacillus Species as Biomarkers for Vaginal Health in Different Community Groups of VMB}

As mentioned above, lactobacilli are dominant species in approximately $70 \%$ of women. Because of the limitations of culture-based approaches, the detection and clustering of the $\mathrm{VMB}$ in different groups is based in the last few years on cultureindependent methods, since culture-dependent methods have some limitations. These molecular techniques include Sanger sequencing of $16 \mathrm{~S}$ rRNA of bacterial colonies (e.g., Verhelst et al., 2005), terminal restriction fragment length polymorphism (T-RFLP) of 16S rRNA (e.g., Zhou et al., 2010), qPCR (e.g., Jespers et al., 2012; Datcu et al., 2013) and next generation sequencing (NGS) (Forney et al., 2010; Hummelen et al., 2010; Ravel et al., 2011; Martin et al., 2012; Smith et al., 2012; Srinivasan et al., 2012; Drell et al., 2013; Lee et al., 2013). Although different techniques have been used, similar patterns have been observed in most studies. For example, Verhelst et al. (2005) were one of the first to categorize the VMB in a number of different grades or community types based on Gram stain, the isolated dominant species, as well as DNA sequencing of $16 \mathrm{~S}$ rRNA genes. More specifically, the authors reported the presence of four vaginal grades. Grade I was characterized by a normal microbiota and has been subsequently separated in grade Ia and Iab, in which $L$. crispatus is the most dominant Lactobacillus species followed by L. jensenii, and $\mathrm{Ib}$, in which $L$. iners and L. gasseri are predominant. In addition, the presence of a grade I-like VMB consists mainly of Bifidobacterium spp. and some lactobacilli, mainly L. gasseri. Grade II represents an intermediate status between grade I and grade III, with the presence of L. iners, L. gasseri, L. crispatus, Atopobium vaginae, Gardnerella vaginalis, Actinomyces neuii and Peptoniphilus. Grade III is characterized by the presence of BVassociated species (Prevotella bivia, A. vaginae, G. vaginalis, Bacteroides ureolyticus and Mobiluncus curtisii) and low amounts of Lactobacillus species, mainly L. iners. Finally, Grade IV is characterized by the presence of a variety of Streptococcus spp. (Verhelst et al., 2005). The results observed by Verhelst et al. were further confirmed in Belgian women in follow up studies performed by the same group (El Aila et al., 2009; Santiago et al., 2011).

Hummelen et al. (2010) reported, by using an Illumina-based amplicon sequencing of the V6 region of the 16S rRNA gene, on the presence of eight major clusters in Tanzanian women, with only two of them associated with a normal microbiota and dominated by L. crispatus and L. iners. The authors also described the presence of four BV-associated clusters, dominated by P. bivia, Lachnospiraceae, or a mixture of different species. The remaining clusters were characterized as normal, intermediate or $\mathrm{BV}$-associated and were dominated mainly by G. vaginalis and L. iners (Hummelen et al., 2010).

Using pyrosequencing of the V1-V2 hypervariable regions of $16 S$ rRNA genes, Ravel et al. (2011) suggested that the VMB can be divided in five major microbial communities based on samples from four ethnic groups-white, black, Hispanic and Asian women in North America. According to the authors, microbial communities belonging to group I (26.2\%), II (6.3\%), III (34.1\%), and V (5.3\%) are dominated by L. crispatus, L. gasseri, $L$. iners, and $L$. jensenii, respectively, and were isolated mainly from white and Asian women (Figure 1), while group IV was characterized by diverse species (see Non-Lactobacillus dominated healthy VMB). Of interest, Smith et al. (2012) observed that the cervical microbiota clusters in six distinct community types of which clusters I-IV are similar to the vaginal community types reported by Ravel and co-workers. The authors were able to detect two additional community types labeled as VI and VII, but were not able to detect a $L$. jensenii dominated microbiota, community type $\mathrm{V}$ as described by Ravel and co-workers. Type VI was characterized by the presence of G. vaginalis, whereas type VII showed high, approximately even proportions of $G$. vaginalis and Lactobacillus spp. An additional cluster designated IIIb, was characterized by a predominance of L. iners (Smith et al., 2012). Srinivasan et al. (2012) observed that women without BV have vaginal bacterial communities dominated either by L. crispatus or L. iners based on 16S rRNA gene PCR and pyrosequencing. Other abundant lactobacilli in women without BV in their study included L. jensenii and L. gasseri, while five women without BV had different dominant bacteria including A. vaginae, Leptotrichia amnionii, Prevotella amii, a first phylogenetically-distinct group of DNA sequences representing BV-associated bacteria (BVAB1) and Fusobacterium gonidiaformans (Srinivasan et al., 2012). Therefore, the actual number of vaginal community types is still under discussion and is driven by the technology used, the sequencing depth, the number of samples of each type, the computational choice made, as well as the underlying data structures. However taken together, the 


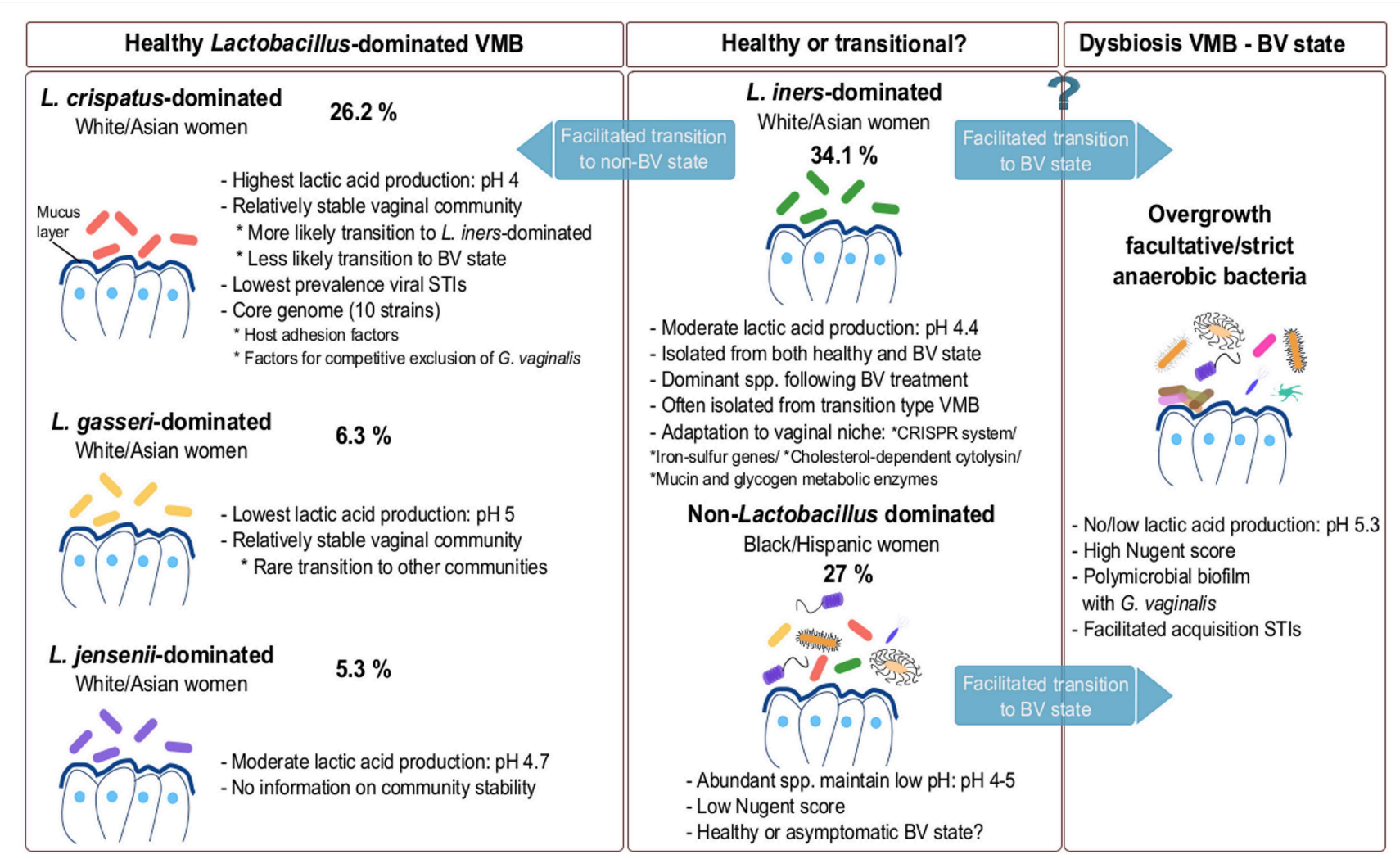

FIGURE 1 | Composition of VMB during healthy and dysbiotic states. The vaginal microbiota in healthy adult premenopausal women can be divided into different community groups. The exact number and type of community groups is still under debate (Verhelst et al., 2005; Ravel et al., 2011; Gajer et al., 2012; Santiago et al., 2012). The most commonly isolated dominating species belong to $L$. crispatus,

L. gasseri, L. iners and $L$. jensenii. The vaginal community group dominated by $L$. iners is also often isolated during menstruation and in the transitional microbiota between healthy and BV state or vice-versa.
Because this species is often isolated during BV, $L$. iners may not be able to effectively protect against pathogens. Additionally, a non-Lactobacillus dominated VMB is also documented in various healthy individuals (Zhou et al., 2004; Ravel et al., 2011; Santiago et al., 2012). For each compositional state, we have added an example of their abundance based on the study of Ravel et al. (2011). However, these numbers are only exemplary and should be considered with caution, as they clearly depend on the study population (size and characteristics) and they certainly need to be substantiated in further studies.
VMB appears to be mainly dominated by L. crispatus and L. iners, while clusters dominated by L. jensenii and L. gasseri appear less common (Figure 1). Of note, L. iners is present in almost all women, including those with dysbiosis, while L. crispatus is typically isolated from healthy women (see L. crispatusdominated microbiota and $L$. iners-harmful or beneficial for vaginal health?). Furthermore, most studies also report clusters without clear dominant species, but instead a proportion of multiple Lactobacillus species. Other Lactobacillus species, such as Lactobacillus rhamnosus (Pascual et al., 2008b), Lactobacillus plantarum (Martin et al., 2008), Lactobacillus vaginalis (Srinivasan et al., 2012), Lactobacillus salivarius (Gustafsson et al., 2011) and Lactobacillus coleohominis (Srinivasan et al., 2012) can also be detected occasionally. A key challenge for future studies on the VMB composition is to integrate and further substantiate the findings of the studies using differing sequencing approaches. Hopefully, this will result in the identification of clinically relevant microbiota clusters that could be good biomarkers of the VMB state. This might be, as compared to the fecal enterotypes (Siezen and Kleerebezem, 2011), more difficult than initially anticipated given the fact that human microbial communities at different body sites appear in a continuum of different compositions, as we will also highlight below for the VMB.

\section{L. crispatus-Dominated Microbiota}

According to the study of Ravel et al. (2011) mentioned above, L. crispatus represents the dominant species of the vaginal bacterial community group I and is isolated mainly from white and Asian women. L. crispatus and L. iners are also detected in group IV that is not dominated by Lactobacillus species. The identification of L. crispatus as the most frequently occurring species, has also been reported in other populations such as Turkish, Swedish, Mexican, Belgian, Japanese, American and Canadian women (Kilic et al., 2001; Vasquez et al., 2002; Verhelst et al., 2005; Ravel et al., 2011; Martinez-Pena et al., 2013; Chaban et al., 2014). Frequent occurrence/dominance of this species has also been reported in pregnant women based on a combined approach of microbiological methods and genus-specific, multiplex and species-specific PCR (Kiss et al., 2007). Apart from its occurrence in the vagina, the species has been reported to be present in the 
rectum of healthy individuals and this colonization appears to be associated with a decreased risk of BV (El Aila et al., 2009).

Recently, a comparative genome analysis of the most abundant vaginal Lactobacillus species explored adaptation mechanisms of vaginal lactobacilli in the vaginal ecosystem (Mendes-Soares et al., 2014). L. crispatus has on average the largest genome with the highest number of proteins unlike the other vaginal strains studied. The L crispatus strains were found to have a unique DNA polymerase, bacteriocin and toxinantitoxin systems and genes encoding mobile genetic elements, especially transposases that contribute to its large genome size. Interestingly, lysogeny of phage particles was observed recently in most of the vaginal isolates of L. crispatus, which could explain the large number of genes encoding mobile genetic elements (Damelin et al., 2011).

van de Wijgert et al. (2014) highlight in their systematic review that longitudinal studies have indicated that a L. crispatus-dominated VMB is more likely to transition to a $L$. inersdominated $\mathrm{VMB}$ and less likely to a dysbiotic state such as $\mathrm{BV}$ and vice-versa. Another study showed that women with a VMB dominated by $L$. crispatus have the lowest prevalence of human immunodeficiency virus (HIV), herpes simplex virus type 2 (HSV-2) and human papillomavirus (HPV) (Borgdorff et al., 2014). In addition, it has been reported that detection of L. crispatus was associated with a $35 \%$ lower risk of HIV-1 RNA shedding (Mitchell et al., 2013).

The presence of BV and loss of lactobacilli appears one of the risk factors of preterm delivery (Donders et al., 2009). For instance, $56 \%$ of women who delivered at term $(n=98)$ were reported in another study to be colonized by two or more species of lactobacilli which included L. crispatus (Petricevic et al., 2014). The exact mechanisms by which lactobacilli could prevent preterm delivery are not known, but pathogen inhibition could be involved. For instance, Escherichia coli infection is a frequent cause of preterm birth (Carey and Klebanoff, 2005) and L. crispatus ATCC 33197 has been shown to contribute to the inhibitory activity of vaginal secretions against E. coli (Ghartey et al., 2014). The exact inhibitory compounds remain to be identified, but many clinical isolates of L crispatus produce $\mathrm{H}_{2} \mathrm{O}_{2}$ in vitro, which has been proposed by Antonio et al. (1999) as an important inhibitory factor against $\mathrm{BV}$ and other pathogens. However, more recent studies show that $\mathrm{H}_{2} \mathrm{O}_{2}$ might not be effective for maintaining vaginal health (O'Hanlon et al., 2010, 2011; Gong et al., 2014). For example, O’Hanlon et al. (2010) did not observe any inhibitory activity of $\mathrm{H}_{2} \mathrm{O}_{2}$ against $G$. vaginalis, P. bivia, Mycoplasma hominis, M. curtsii, Mobiluncus mulieris, HSV-2, N. gonorrhoeae and Hemophilus ducreyii. The authors also observed that in order to have efficient $\mathrm{H}_{2} \mathrm{O}_{2}$ production in vitro, vigorous agitation to increase aeration is essential, which has been supported by other authors as well (Strus et al., 2006; Martin and Suarez, 2010). The low in vivo concentrations of $\mathrm{H}_{2} \mathrm{O}_{2}$ could therefore be explained by the relatively hypoxic environment of the vaginal lumen. Higher aeration and therefore production of $\mathrm{H}_{2} \mathrm{O}_{2}$ could possibly be achieved by sexual intercourse, although cervicovaginal fluid and semen have been shown to inactivate $\mathrm{H}_{2} \mathrm{O}_{2}$ (O'Hanlon et al., 2010; Gong et al., 2014). In a follow up study, the authors observed that under anaerobic growth conditions, physiological concentrations of lactic acid (55-111 mM) inactivated various $\mathrm{BV}$-associated bacteria, while physiological concentrations of $\mathrm{H}_{2} \mathrm{O}_{2}(<100 \mu \mathrm{M})$ showed no inactivation of the tested BV-associated bacteria, suggesting that lactic acid might be significantly more protective against infections in the vaginal environment in comparison to $\mathrm{H}_{2} \mathrm{O}_{2}$ (O'Hanlon et al., 2011). Moreover, at a concentration of $10 \mathrm{mM}$, $\mathrm{H}_{2} \mathrm{O}_{2}$ was more toxic to vaginal lactobacilli than to BV-associated bacteria (O'Hanlon et al., 2011). Of note, $\mathrm{H}_{2} \mathrm{O}_{2}$ has been investigated for clinical treatment of $\mathrm{BV}$. For example, Cardone et al. (2003) showed that addition of $3 \% \mathrm{H}_{2} \mathrm{O}_{2}$ for 1 week in the vaginal niche could eliminate the symptoms of BV and facilitate the restoration of a normal Lactobacillus dominated microbiota (Cardone et al., 2003). However, another study using single vaginal douching with $3 \% \mathrm{H}_{2} \mathrm{O}_{2}$ failed to observe any positive results as compared to the metronidazole control group (Chaithongwongwatthana et al., 2003), indicating that $\mathrm{H}_{2} \mathrm{O}_{2}$ is not a key active metabolite of vaginal lactobacilli.

Therefore, the inhibition of E. coli and other BV-associated bacteria by L. crispatus is probably a result of lactic acid production or other not yet known factors. For example, Ravel et al. (2011) observed that $L$. crispatus-dominated communities have a lower vaginal $\mathrm{pH}$ as compared to communities dominated by other species, suggesting that $L$. crispatus is one of the highest producers of lactic acid, which is a key antimicrobial product of lactobacilli. Witkin et al. (2013) found that D-lactic acid, present in the highest amount in vaginal secretions of L. crispatus-dominated women, can inhibit extracellular matrix metalloproteinase inducer (EMMPRIN) production. EMMPRIN induces matrix metalloproteinase 8 (MMP-8), which is suggested to make the vaginal barrier more prone to upper genital infections linked to preterm birth. This might thus imply that D-lactic acid production is an important factor in the protection against preterm delivery. Moreover, L. crispatus can also have beneficial effects via immunomodulation. For example, L. crispatus ATCC 33820 was shown to inhibit Candida albicans in vitro, via modulation of Toll-like receptors (TLR) 2/4, interleukin 8 (IL-8) and human $\beta$-defensin 2 and 3 expression in epithelial cells (HeLa) (Rizzo et al., 2013). Taken together, these studies clearly suggest that the prevalence of L. crispatus in the VMB is an indicator of a healthy vaginal microbial ecosystem.

\section{L. iners-Harmful or Beneficial for Vaginal Health?}

L. iners is one of the most commonly observed vaginal species, but was not commonly isolated since it is difficult to grow. It has been reported from both healthy and BV-diagnosed women, in contrast with L. crispatus which is mainly isolated from healthy women. The species was discovered by Falsen et al. (1999) and has escaped the attention of scientists for a long time, since it grows only on blood agar, but not on MRS or Rogosa (Falsen et al., 1999). L. iners has been detected in healthy Swedish women (determined by Nugent score), Canadian (with a normal Nugent score) (Burton and Reid, 2002), Nigerian (determined by Nugent score) (Anukam et al., 2006c), Brazilian (determined by Gram staining) (Martinez et al., 2008) and apparently healthy Chinese women (Shi et al., 2009). Ravel et al. (2011) showed that 
microbial communities belonging to group III (34.1\%) of healthy white American and Asian women are dominated by L. iners as described above. Srinivasan and co-workers also reported that the VMB of $93 \%$ of American women without BV, as determined by Gram staining, are dominated by L. iners or L. crispatus (Srinivasan et al., 2012). However, the authors also observed that women with high levels of $L$. iners could be either BV positive or negative, demonstrating that the presence of $L$. iners as dominant Lactobacillus species might not be sufficient to protect against BV, in contrast to the conditions in which other Lactobacillus species dominate. Of note, other studies also detected L. iners during BVassociated conditions using different analysis methods (Burton and Reid, 2002; El Aila et al., 2009; Hummelen et al., 2010; Santiago et al., 2011). Interestingly, Witkin et al. (2013) showed that L. iners-dominated women have lower concentrations of D-lactic acid, suggesting that this could be one of the factors explaining the prevalence of BV in these women. This was also corroborated by their in vitro studies and genome analysis of $L$. iners which showed the incapability of the species to produce D-lactic acid (Witkin et al., 2013). Furthermore, L. iners has often been identified in the microbiota types intermediate between BV and normal microbiota. For example, L. iners was found to be dominant even after treatment of BV with metronidazole gel as studied by Ferris et al. (2007), and further supported by Jakobsson and Forsum (2007). The dominance of $L$. iners after treatment of BV (Srinivasan et al., 2012; Shipitsyna et al., 2013) led to the suggestion that $L$. iners might facilitate the transition between BV and non-BV states. It has been reported that a L iners dominant state does not convert to a L. crispatus-dominated state even after BV treatment (Lambert et al., 2013). Additionally, L. iners was found to overgrow during menstruation, while the number of L. crispatus decreased (Srinivasan et al., 2010, 2012; Gajer et al., 2012; Santiago et al., 2012). Furthermore, Petricevic et al. (2014) observed that when $L$. iners was present alone without the presence of any other Lactobacillus species in pregnant women $(n=27)$, $40.7 \%$ of these women delivered preterm. Although the authors concluded on an association between solely L. iners presence in healthy pregnant women and preterm delivery, these results are not based on a well-controlled study population including 98 women who delivered at term and only 13 women who delivered preterm, requiring further studies.

Taking all data above together, the current data thus suggest that the presence of $L$. iners is not merely a biomarker reflecting a healthy human VMB. Of interest, the strain L. iners AB-1 has an unusually small genome of $\sim 1.3 \mathrm{Mbp}$ single chromosome, which seems to have undergone one or more rapid evolution events resulting in massive gene loss and acquisition of genes for optimal survival in the vaginal body site, such as iron-sulfur genes (Macklaim et al., 2011). The strain's genome encodes several genes that allow it to respond adequately to rapid changes in the environment, including CRISPR regions for phage resistance and genes for glycogen utilization, and maltose and mannose uptake. Interestingly, these genes appear to be over-expressed only during BV and not under normal healthy conditions (Macklaim et al., 2013). Additionally, the small genome size of L. iners may be indicative of a symbiotic or parasitic lifestyle in contrast to other lactobacilli that show niche flexibility and genome sizes of ca. 3 Mbp. Mendes-Soares et al. (2014) studied the genomes of several $L$. iners strains and found that all the strains lack several integral membrane proteins, protein families related to the acetyltransferase GNAT (Gcn5-related N-acetyltransferases) family and various transcriptional regulators present in other vaginal strains whereas they possess numerous $\mathrm{ABC}$ transporter permeases absent in other strains (Mendes-Soares et al., 2014). L. iners strains encode for inerolysin, a cholesterol-dependent pore-forming toxin, related to the vaginolysin virulence factor of G. vaginalis (Rampersaud et al., 2011). Therefore, further studies are needed to determine the exact role of this interesting species in vaginal health and disease and whether this strain is merely a biomarker of a vaginal microbiota in transition or could sometimes be a contributing factor to $\mathrm{BV}$, as further discussed below.

\section{Non-Lactobacillus Dominated Healthy VMB}

As mentioned above, recent studies also reported the presence of non-Lactobacillus dominated VMB in ca. $20-30 \%$ of healthy women (Zhou et al., 2010; Ravel et al., 2011; Srinivasan et al., 2012). These kind of vaginal communities are dominated by facultative or strict anaerobes, such as Gardnerella, Corynebacterium, Atopobium, Anaerococcus, Prevotella, Peptoniphilus, Mobiluncus, Sneathia, Finegoldia, and Eggerthella. Such diverse VMB appears to be typical for black and Hispanic women (Ravel et al., 2011). It is still debated whether this type of microbiota is thoroughly reflecting a healthy state or rather an asymptomatic state of BV. Previous studies suggested that even though this type of microbiota is non-lactobacilli dominated, the abundant species are able to maintain the crucial protective function of the vaginal niche, i.e. a low vaginal $\mathrm{pH}$ by production of lactic acid (Gajer et al., 2012). For example, members from Atopobium, Streptococcus, Staphylococcus, Megasphaera, and Leptotrichia are capable of homolactic or heterolactic acid fermentation (Zhou et al., 2004). Therefore, in the absence of symptoms, it appears that this type of diverse microbiota is normal and healthy. Nevertheless, a close and regular monitoring of women harboring a diverse type of VMB might be warranted to reduce the risk of BV, STIs or other problems in apparently healthy women, but who might have problems with fertility and preterm delivery.

\section{Temporal Shifts in the Composition of VMB}

Most of the available studies on VMB are cross-sectional studies and thus only based on the collection of vaginal samples at a single time point. Nevertheless, the vaginal communities can change drastically over time based on changes in hormone levels, antibiotic treatments, sexual activities and/or hygiene practices. Therefore, a few recent prospective longitudinal studies examined the dynamics of the VMB, although mostly over a short period of time. For instance, the number of $L$. iners appears to remarkably increase during menses along with an increase of $G$. vaginalis, while they subsequently decrease after menses without intervention. Instead, the VMB dominated by L. crispatus appears to remain stable during menses (Srinivasan et al., 2010). The group of Vaneechoutte and co-workers reported that menses immensely disturbs the diversity of the VMB (Santiago 
et al., 2012). They observed a 100-fold decline in L. crispatus during menses, while the numbers of $L$. iners, G. vaginalis, $A$. vaginae, and $P$. bivia drastically increased in women with a normal microbiota (Santiago et al., 2012). They even reported that women with grade III VMB (diverse BV-associated state) had a more stable VMB than women with normal (grade I) microbiota. Gajer et al. (2012) also showed that the vaginal bacterial communities of some women markedly change over time, switching from one class to another, whereas others stay relatively stable. L. crispatus-dominated communities appear to often transform to a community state III dominated by L. iners, or to IV-A which is heterogeneous in composition and is characterized by a modest proportion of L. crispatus, L. iners or other Lactobacillus species as well as low numbers of strict anaerobic bacteria. L. iners-dominated communities shift more often to community type IV-B, which is dominated by a diverse number of bacteria belonging mainly to the genus Atopobium, Prevotella, Parvimonas, Sneathia, Gardnerella, or Mobiluncus, but in rare cases to IV-A. L. gasseri-dominated community groups rarely transit to other types and stay stable over time. The fluctuation of vaginal communities was affected by time in the menstruation cycle and to a certain extent by sexual activity (Gajer et al., 2012). Taken together, the studies of Srinivasan et al. (2010), Santiago et al. (2012) and Gajer et al. (2012) established (i) an important inter-individual variability in the VMB, (ii) a strong reduction of $L$. crispatus and its replacement by $L$. iners or by Gram positive cocci during menstruation, and (iii) long term stability of the VMB for only some women, which increases when L. crispatus is the dominant species. However, other studies show a different outcome. For instance, Chaban et al. (2014) did not observe any significant changes in the VMB during specific menstrual phases using cpn60-based analysis, although data of only 26 women were analyzed in this study. Nevertheless, all these studies on temporal shifts are in agreement with one of the major conclusions of the Human Microbiome Project that within-subject microbiota variation over time is lower than between-subject variation for all body sites, including the vagina (Human Microbiome Project Consortium, 2012).

\section{Lactobacillus Species Promote Vaginal Health by Lowering the Risk of BV}

As yet introduced, one of the most common vaginal disorders is BV affecting fertile, premenopausal and pregnant women, resulting in millions of health care visits annually around the world. $\mathrm{BV}$ is a complex, polymicrobial disorder characterized by the disruption of the vaginal econiche, resulting in a reduction of lactobacilli and an overgrowth of strict or facultative anaerobic bacteria such as Gardnerella spp., Atopobium spp., Prevotella spp., Mobiluncus spp., as well as other taxa such as Clostridium spp., Megasphaera spp., Leptotrichia spp., and Eggerthella-like bacteria that were found even in pregnant women (Verstraelen et al., 2004; Fredricks et al., 2005; Tamrakar et al., 2007). Despite multiple attempts and focused research in the last decades to determine the exact cause of BV, the evidence is still poor. Multiple factors are reported to be involved in the development of
$\mathrm{BV}$, such as hormonal changes, the number of sexual partners, smoking, personal hygiene and antibiotic treatment (Hellberg et al., 2000; Verhelst et al., 2004; Brotman et al., 2008, 2014a). In recent years, culture-independent techniques based on the analysis of $16 \mathrm{~S}$ rRNA gene sequences as described above have identified 3 phylogenetically-distinct DNA sequences representing potentially $\mathrm{BV}$-associated bacteria (BVAB) BVAB1, BVAB2, and BVAB3, which are distantly related to the species of the phyla Actinobacteria and Firmicutes. BVABs, more specifically BVAB2, together with Megasphaera, Leptotrichia, and Eggerthella-like bacteria were found to be more representative species of BV than Gardnerella and Atopobium (Fredricks et al., 2005). Fluorescent in-situ hybridization (FISH) analysis by Swidsinski and coworkers revealed the presence of a dense polymicrobial biofilm on the vaginal epithelial surface in biopsies of women with BV. This biofilm is assumed to be initiated by $G$. vaginalis strains, which then becomes a scaffold for other species to adhere (Swidsinski et al., 2010; Verstraelen and Swidsinski, 2013). It is still uncertain whether these species are actually involved in the development of $\mathrm{BV}$ and therefore can be considered as pathogens, or if they are opportunistic organisms which are well adapted to the changes in the vaginal environment, as described for $L$. iners (see L. inersharmful or beneficial for vaginal health?). When symptomatic, $\mathrm{BV}$ is characterized by vaginal discomfort and homogeneous malodorous vaginal discharge. Two methods are used for diagnosis of BV: the Amsel criteria and the Nugent scoring system. The Amsel criteria are often used in clinical practice (Amsel et al., 1983) and require the presence of at least three of the following criteria to diagnose BV: (i) thin, homogeneous vaginal discharge; (ii) vaginal $\mathrm{pH}$ higher than 4.5; (iii) "fishy" odor of vaginal fluid before or after addition of $10 \%$ potassium hydroxide (KOH) (whiff test); (iv) presence of clue cells on microscopic evaluation of saline wet preparations. However, the use of Amsel criteria is debatable, especially during pregnancy, when increased vaginal discharge is observed (Guise et al., 2001). There is not a major difference in the prevalence of vaginal discharge and odor among women with or without BV, which together with the fact that women often do not report any vaginal discharge, wetness, or odor makes the criteria subjective (Klebanoff et al., 2004). In addition, the $\mathrm{pH}$ value of the samples depends on how and where the samples are exactly taken. Secondly, the Nugent score is based on the Gram staining of vaginal smears and includes the microscopic quantitation of bacterial morphotypes yielding a score between 0 and 10 (Nugent et al., 1991). A score of 0-3 is normal, 4-6 is intermediate, and $7-10$ is considered as BV. Important to mention is that around $50 \%$ of all women with BV as determined by Nugent score are asymptomatic. It is still unclear whether these women are asymptomatic or the symptoms are insignificantly pronounced and therefore poorly recognized and under-reported. These asymptomatic and most of the time non-inflammatory BV conditions can have important clinical consequences. For example, it has been reported that changes in the VMB are associated with various vaginal and urinary tract infections (Harmanli et al., 2000; Koumans et al., 2002). Furthermore, BV may result in increased rates of early pregnancy loss and preterm delivery (Eckert et al., 2003; Verstraelen et al., 2005). It has also been shown that $\mathrm{BV}$ facilitates the acquisition of sexually transmitted infections 
such as Neisseria gonorrhoeae, Chlamydia trachomatis, HIV and HSV-2 (Martin et al., 1999; Cherpes et al., 2003b; Wiesenfeld et al., 2003). Moreover, genital tract shedding of HIV, HSV-2 (Cherpes et al., 2005) and cytomegalovirus (Ross et al., 2005) is significantly higher in women with $\mathrm{BV}$ compared to $\mathrm{BV}$-free women.

Several mechanisms have been proposed to explain how BV could increase the risk of STIs acquisition. First, the loss of protective Lactobacillus species and other changes in the vagina, such as elevated $\mathrm{pH}$ and decreased lactic acid concentrations, related to BV could facilitate the survival of vaginal pathogens. Secondly, BV-related microorganisms produce mucin-degrading enzymes in the vaginal fluid (e.g., sialidases), which degrade the mucus coating the vaginal and cervical epithelium, considered as one of the major components of the barrier against infection. Macklaim et al. (2013) also reported that the metabolome during BV conditions differs from the healthy stage. For example, the BV samples were enriched of enzymes, which belong mainly to $P$. amnii and some to $G$. vaginalis, used for the metabolism of glycans and more precisely of glycogen. The overexpression of those enzymes results in the production of succinate and short-chain fatty-acids, while healthy conditions are characterized by a high level of lactic acid. This mucus and glycogen degradation may cause micro-abrasions or epithelial cell alterations which could facilitate binding of pathogens to the underlying epithelial cell receptors. Finally, the immunological balance in the vaginal tract appears to be changed during BV with increased levels of pro-inflammatory cytokines which could render women more susceptible to the acquisition of STIs (Brotman, 2011; Gillet et al., 2011; Nardis et al., 2013).

Taken together, different studies on BV show different outcomes, which can be partially explained by the different diagnostic criteria used (e.g., Nugent score vs. Amsel criteria). There exists thus a clear need to complement these methods with culture-dependent and NGS methods to better diagnose BV and characterize the VMB.

\section{Lactobacillus Species Promote Vaginal Health by Lowering the Risk of STIs}

STIs can be caused by over 30 bacterial, viral and parasitic pathogens known to be transmitted sexually, including vaginal, anal and oral sex. Important pathogens with a high incidence include bacterial pathogens such as C. trachomatis, $N$. gonorrhoea and viral pathogens such as HIV, HSV-2 and HPV. Since these infections have a considerable impact on reproductive and general health, STIs belong to the top five disease categories for which adults seek medical attention. Moreover, the majority of STIs remain asymptomatic which implies increased transmission risks of STIs. As described above, Lactobacillus species are thought to be a valuable biomarker for vaginal health supported by the fact that the presence of BV increases the risk of STIs acquisition. Therefore, a better understanding of the relationship between the vaginal microbiome and risk of STIs combined with refined biomarkers for a healthy VMB may lead to new strategies aiming at maintaining and/or restoring more protective vaginal bacterial communities.

\section{Bacterial STIs and the VMB}

C. trachomatis infection is one of the most common bacterial STIs worldwide, with an estimated number of 105.7 million new infections annually in 2008. Untreated chlamydia may lead to pelvic inflammatory disease, tubal infertility and ectopic pregnancy. BV was found to be a strong predictor of C. trachomatis and $N$. gonorrhoeae infection among women with recent exposure to a male partner with chlamydial or gonococcal urethritis (Wiesenfeld et al., 2003). Another longitudinal study identified a significant association between intermediate/high Nugent score and increased risk of incident trichomonal, gonococcal and chlamydial infection (Brotman et al., 2010). Furthermore, longitudinal, randomized study observed that metronidazole treatment of BV-positive women for 1 year had significantly lower incidences of Chlamydia, however no appropriate placebo control was used (Schwebke and Desmond, 2007). Multiple studies thus suggest that BV increases the risk of incident C. trachomatis infection. Interestingly, combined $16 \mathrm{~S}$ rRNA sequencing and metagenomics on vaginal samples of $101 \mathrm{C}$. trachomatis-infected women (92\% African-American) treated at diagnosis revealed low proportions of Lactobacillus or specific L. iners genome types as a hallmark of the chlamydia infected state (Ma et al., 2013a).

$N$. gonorrhoeae is the second most common bacterial STIs affecting around 36.4 million adults worldwide in 2008. This Gram-negative bacterium causes infections of the female cervix, but also of the vagina, pharynx and rectum (Vielfort et al., 2008). As described above, multiple studies describe associations between BV and N. gonorrhoea infection. Given that the initial interaction between $N$. gonorrhoeae and the epithelial cells of the host is critical for successful colonization of the mucosa (Vielfort et al., 2008), several in vitro studies focused on the ability of vaginal lactobacilli to inhibit gonococcal adherence to epithelial cells. For example, it has been shown that L. jensenii ATCC 25258 could both reduce adhesion and invasion of N. gonorrhoeae, whereas L. gasseri ATCC 33323 could displace adherent N. gonorrhoeae (Spurbeck and Arvidson, 2008). A follow up study determined that released surface components (RSC) of L. jensenii ATCC 25258 are able to inhibit N. gonorrhoeae interaction with endometrial epithelial cells in vitro by occluding fibronectin binding sites. Future experiments are required to verify whether the surface-located enolase protein, identified as the main gonococcal adherence inhibiting factor of the RSC, is indeed the fibronectin-binding protein (Spurbeck and Arvidson, 2010). Nevertheless, future in vivo studies need to validate the importance of adherence competition in pathogen inhibition, in addition to more direct antimicrobial mechanisms of lactobacilli (see further).

\section{Viral STIs and the VMB}

HIV infections remain one of the major global public health issues to date, accompanied by an estimated direct total lifetime medical cost of 12.6 billion dollars in the US in 2008 (OwusuEdusei et al., 2013). By the end of 2013, approximately 35 million people were living with HIV and this number is increasing by 
around 2.1 million new infections each year. In order to increase the possibility for new therapies, a better understanding of the interplay between the VMB and HIV infections could be of crucial importance. A significant association was detected between women with BV, and thus lack of predominant Lactobacillus spp., and increased susceptibility to HIV acquisition (Atashili et al., 2008; Low et al., 2011). Furthermore, the prevalence and incidence of HSV-2 infections as well as the incidence of N. gonorrhoeae infections appear to be independent risk factors for HIV acquisition (van de Wijgert et al., 2009). Possible mechanisms for this relationship include (i) activation of immune response and inflammation during BV, (ii) disruption of the vaginal epithelium through which HIV could reach its target immune cells, and (iii) decreased Lactobacillus spp. causing elevated $\mathrm{pH}$ and lowered $\mathrm{H}_{2} \mathrm{O}_{2}$ concentrations (Petrova et al., 2013). Furthermore, BV is also often detected in HIV-seropositive women (Spear et al., 2011; Borgdorff et al., 2014). HIV-positive women with BV are characterized by a higher bacterial diversity compared to HIV-negative women with BV (Spear et al., 2008). Other studies also detected an association between $\mathrm{BV}$ and increased viral replication and HIV shedding suggesting that BV may have a role in enhancing HIV infectivity (Sha et al., 2005; Coleman et al., 2007; Tanton et al., 2011). Of note the presence of G. vaginalis, M. hominis, and $P$. bivia was also related to increased HIV expression whereas L. acidophilus was not (Hashemi et al., 2000). In addition, BV has been also associated with increased rates of transmission of HIV from infected women to their male partners, which suggests that BV could be responsible for new HIV-1 infections in Africa (Cohen et al., 2012). More detailed information on the antiviral mechanisms are discussed elsewhere (Petrova et al., 2013).

HSV-2, the main cause of genital herpes disease, is affecting around $20 \%$ of the female worldwide population in 2008 aged between 15 and 49 years (Looker et al., 2008). In order to better understand the relationship between the VMB and HSV-2 infections, multiple studies focused on the association between BV and HSV-2. Of note, the relationship between BV and HSV-2 is found to be potentially bidirectional. Several studies, some with longitudinal and some with cross-sectional study design, identified BV and the lack of Lactobacillus-predominant microbiota as an independent risk factor of HSV-2 acquisition (Cherpes et al., 2003a,b; Gottlieb et al., 2004; Kaul et al., 2007; Gallo et al., 2008). Moreover, a longitudinal study performed in the US described BV as a risk factor for HSV-2 replication and genital tract shedding, which can enhance the spread of HSV-2 (Cherpes et al., 2005). Evidence was also found that BV prevalence is higher after HSV-2 seroconversion in a female African population (Kaul et al., 2007; Nagot et al., 2007; Masese et al., 2014), for which Masese and colleagues described that incident HSV-2 was associated with a $30 \%$ increase in odds of episodes of BV. This association was also identified within female US populations (Allsworth et al., 2008; Cherpes et al., 2008). More specifically, positive HSV-2 serology is a risk factor for acquisition or subsequent episodes of BV (Cherpes et al., 2008; Masese et al., 2014). Prevalent HSV-2 infection was also associated with increased incidence of Trichomonas vaginalis and N. gonorrhoeae (Kaul et al., 2007). Of note, all studies mentioned above diagnosed BV by Nugent scoring and HSV-2 by PCR or serology testing. HSV-2 infection can also increase the rate of HIV-1 acquisition (Minton, 2013). To date, direct and indirect mechanisms could be responsible, with co-infection of cells by HIV and HSV-2 as a potential direct mechanism, which appeared unlikely based on infection results of an ex vivo skin explant model (Minton, 2013). Indirect mechanisms include disruption of epithelial barriers by HSV-2 and further inflammation, resulting in the recruitment of $\mathrm{T}$ lymphocytes and therefore increased episodes of HIV (Zhu et al., 2009). Furthermore, HSV2 has also been shown to induce expression of an antimicrobial peptide LL-37 by keratinocytes, which is able to increase the susceptibility of Langerhans cells to HIV-1 due to increased expression levels of HIV coreceptors CD4 and CCR5 (Ogawa et al., 2013). Therefore, strategies to inhibit HSV-2 infection may also benefit indirect prevention of HIV-1 infections.

A third class of viral STIs which should not be underestimated consists of HPV infections. There are more than 100 types of HPV of which 13 are identified as high risk HPV types able to cause cervical cancer. Multiple studies have identified a positive association between BV and cervical HPV infection, supported by the overall estimated odds ratio of a meta-analysis including 12 eligible studies investigating the BV-HPV association (Gillet et al., 2011). BV was associated with the acquisition or reactivation of HPV infection, whereas no association was found with HPV persistence or the development of squamous intraepithelial lesions (SIL) (Watts et al., 2005). However, others observed a decreased or slower clearance of HPV lesions in women diagnosed with BV (Guo et al., 2012; Brotman et al., 2014b). More detailed molecular studies indicated that HPV infection seems to be associated with changes in the composition of the VMB, namely with a decrease in lactobacilli and increase in microbiota diversity (Clarke et al., 2012; Dols et al., 2012; Gao et al., 2013; Lee et al., 2013). These data are supported by the fact that a vaginal $\mathrm{pH}$ above 5 resulted in a $10-20 \%$ increased HPV risk and is associated with low-grade SIL diagnosis, as identified in premenopausal women from Costa Rica (Clarke et al., 2012). During HPV infection, L. crispatus was less frequently and L. gasseri and G. vaginalis were more frequently isolated from vaginal samples (Dols et al., 2012; Gao et al., 2013). A close study of a Korean twin cohort revealed an association between HPV and the abundance of Fusobacteria. In particular, Sneathia spp. were identified as potential microbiological markers of HPV infection, although the specificity for HPV should be further verified (Lee et al., 2013). Recently, a significant association between microbiota community types, as described by Gajer et al. (2012) using the same vaginal samples, and remission of HPV infection was observed. Apart from clusters III and IV having a greater proportion of HPV infections compared to other clusters, group IV-A increased the risk for transition to a HPV-positive state and group IV-B showed the slowest HPV clearance rate (Brotman et al., 2014b). In general, microbiota dominated by $L$. iners or lacking sufficient numbers of lactobacilli may represent microenvironments with increased risk of HPV acquisition/persistence (Brotman et al., 2014b). Taken together, reduced Lactobacillus counts are associated with HPV infection. Therefore, the rational selection of Lactobacillus probiotics with potential impact on HPV risk may represent a valuable strategy to lower HPV incidences/persistence. In a first longitudinal pilot study, $54 \mathrm{HPV}$-positive and low-grade SIL-positive women 
consumed a probiotic drink containing L. casei Shirota every day for 6 months. Probiotic users were twice as likely to have cervical lesion clearance, although no change in HPV detection was observed (Verhoeven et al., 2013). Further research is required to determine if probiotic interventions are able to reduce productive and/or recurrent HPV infections, as well as other viral STIs, since the current evidence is very limited.

Finally, we want to highlight the importance of well-designed clinical studies, which should include a statistically significant number of well-characterized women sampled longitudinally and which should control for potential confounding factors such as sociodemographic/economic, (sexual) behavioral and microbiological factors in order to define the exact role of the VMB in STIs, as well as to define the exact VMB communities. Primarily, attention should be given to the design of clinical studies examining associations between STIs and potential risk factors, which can be longitudinal or cross-sectional. Longitudinal studies, analyzing multiple samples per individual taken at follow up visits have the advantage to provide information on a causal relationship and possible fluctuations in STI episodes or VMB composition. Cross-sectional studies, analyzing only one sample per individual can only suggest association and should be taken within a representative time frame (e.g., not within menses, active/passive HSV-2 infection, etc.). Secondly, clinical data obtained should be adjusted for potential confounding factors of which important ones are age, race, sexual activity, condom use, number of sexual partners, time of menstruation, use of antibiotics, hormonal contraception, vaginal douching and BV/STI prevalence and episodes. For instance, it has been recently reported that use of condoms is associated with $L$. crispatus colonization of the vagina, which has also been shown to be protective against BV (as well as other STIs) (Ma et al., 2013b), indicating that it is an important confounding factor.

\section{How Vaginal Lactobacilli Exert Their Health Promoting Effects}

Since lactobacilli appear to be a hallmark of a healthy vaginal ecosystem, it is important to understand how they can exert important health-promoting effects, because knowledge on the exact molecular mediators can also promote the discovery and implementation of biomarkers. Postulated direct and indirect anti-pathogenic mechanisms of lactobacilli include (i) production of lactic acid and bacteriocins that directly kill or inhibit bacterial and viral pathogens, (ii) formation of microcolonies that adhere to the epithelial cell receptors and form a physical barrier against pathogen adhesion (Petrova et al., 2013), and (iii) stimulation of host defense mechanisms against pathogens (Lebeer et al., 2010). Yet again, although the health benefits of vaginal lactobacilli are widely recognized, they have been poorly substantiated by molecular studies.

\section{Production of Lactic Acid and Bacteriocins}

Directly linked to the presence of lactobacilli, the production of lactic acid is accepted as a hallmark beneficial activity of the VMB. Lactic acid has been linked to pathogen exclusion and their concentrations could also be seen as important biomarkers of vaginal health, although the current evidence is still mainly based on in vitro studies. For example, it has been shown that lactic acid is able to inactivate a wide range of reproductive tract pathogens, including the uropathogenic E. coli (Juarez Tomas et al., 2003), N. gonorrhoeae (Graver and Wade, 2011), and C. trachomatis (Gong et al., 2014). However, for the latter, similar inactivation was identified for formic acid and acetic acid, suggesting that sufficient hydrogen ions are involved in the mechanism to kill Chlamydia (Gong et al., 2014). Furthermore, a strong pH-independent inhibition of C. trachomatis by L. brevis CD2 (DSM 11988) could also be observed during early steps of infection. The same strain was also able to inhibit HSV-2-induced Chlamydia persistence (Mastromarino et al., 2014). Lactic acid has also been shown to play an important role in direct inactivation of HSV-2 (Conti et al., 2009) and HIV-1, due to effective capturing by acid cervicovaginal human mucus (Lai et al., 2009; Shukair et al., 2013). Given these data, lactic acid has been investigated for clinical treatment of BV. For example, re-establishment of the normal Lactobacillus dominated microbiota after the use of lactic acid gels has been reported for both pregnant and non-pregnant women after a few days of treatment (Andersch et al., 1986; Holst and Brandberg, 1990). However, another study failed to observe any positive results (Boeke et al., 1993), suggesting that well-designed clinical studies are required in order to investigate the possibility of using lactic acid as an alternative BV treatment.

Bacteriocins represent another main mechanism of direct inhibition of pathogens. Bacteriocins are known as ribosomally synthesized antimicrobial peptides and proteins with activity against closely related microorganisms (Cotter et al., 2013), although, as recently reported, several bacteriocins have a wide activity against unrelated microorganisms and viruses. For example, it has been shown that $\mathrm{L} 23$ bacteriocin $(7 \mathrm{kDa})$ produced by Lactobacillus fermentum L23 displays a wide inhibitory activity against Gram-negative and Gram-positive pathogenic strains and Candida spp. (Pascual et al., 2008a). Fermenticin HV6b (class IIa antimicrobial peptide), produced by L. fermentum HV6b MTCC 10770, shows growth inhibition of G. vaginalis, Mobiluncus, staphylococci and streptococci (Kaur et al., 2013). In another study, Donia et al. (2014) were able to purify and reveal the structure of a thiopeptide antibiotic, named lactocillin, produced by reference strain L. gasseri JV-V03. Lactocillin has been shown to possess activity against $S$. aureus, Enterococcus faecalis, G. vaginalis, and Corynebacterium aurimucosum (Donia et al., 2014).

\section{Adhesion}

Adherence of vaginal lactobacilli to host cells has been shown to prevent colonization by pathogenic microorganisms in vitro (Osset et al., 2001; Atassi et al., 2006) and in vivo (Anukam et al., 2006b). Hereby, the adherence pattern of lactobacilli appears to be more loose than that of (BV) pathogens that occur in thicker biofilms (Machado et al., 2013). Various cell surface components (proteins/glycoproteins, exopolysaccharides) of GI lactobacilli have been shown to play a role in bacterial adhesion to the host/pathogens (Lebeer et al., 2010). However, information on adhesins in vaginal Lactobacillus strains is lagging behind. Several vaginal Lactobacillus isolates have been shown to block 
the adhesion of vaginal pathogens to vaginal epithelial cells in vitro, such as by displacement and competition. For example, displacement of $G$. vaginalis by various lactobacilli has been reported (Mastromarino et al., 2002). Furthermore, exclusion and competition of $S$. aureus, Group B streptococci (Zarate and Nader-Macias, 2006), Pseudomonas aeruginosa, Klebsiella pneumonia, and E. coli (Osset et al., 2001), uropathogenic E. coli (UPEC), G. vaginalis and P. bivia (Atassi et al., 2006), and of T. vaginalis (Phukan et al., 2013) by Lactobacillus species have also been observed. An in vitro anti-HSV-2 activity of vaginal L. brevis, L. plantarum, and L. salivarius isolates was shown to be directly dependent on the adhesiveness of each bacterial strain to human epithelial cells (Mastromarino et al., 2002, 2011).

Interestingly, the genomes of the recently sequenced vaginal lactobacilli have been shown to encode various adhesins that could have a role in pathogen exclusion. For instance, the genome of L. pentosus KCA1 codes for large-sized mucus-binding and fibrinogen-binding proteins (FbpA) (Anukam et al., 2013). Recently, we were able to show that the genome of L. plantarum CMPG5300 contains many putative adhesion proteins, including predicted collagen-binding, mucus-binding, chitin-binding, fibrinogen-binding and mannose-binding proteins (Malik et al., 2014). The binding of $L$. iners AB-1 to fibrinogen has been suggested to be associated with the involvement of its genomeencoded fibrinogen-binding protein (McMillan et al., 2013), although this remains to be further validated, for example, by mutational analysis. A comparative genomic approach highlights that the strong adhesive capacity of L. crispatus and some unique adhesins play a key role in competitive exclusion of important BV pathogens such as Gardnerella vaginalis (Ojala et al., 2014). Although the exact role of specific adhesins in the adhesion of vaginal Lactobacillus species to host cells remains to be further explored, it becomes apparent that (loose) adherence of lactobacilli could be a biomarker of vaginal health. The rapid detection of specific Lactobacillus spp., such as L. crispatus detection in the human vagina by FISH approaches (Machado et al., 2013), could thus hold promise as novel molecular biomarkers of vaginal health.

\section{Stimulation of Host Defense Mechanisms}

Finally, lactobacilli probably also promote health in the vaginal ecosystem via various immunomodulation mechanisms, although this role is still poorly understood and mainly based on in vitro work. For example, Rose et al. (2012) reported that when the vaginal epithelial cells (VEC) were subjected to TLR agonists, L. crispatus ATCC 38820 and L. jensenii ATCC 25258 were able to temper the immune response. Furthermore, cytokine profiles of VEC were not affected after colonization with these commensal vaginal strains. However, the anti-inflammatory effect of the lactobacilli differed amongst agonists and strains, indicating that the immune-modulating effect of commensal strains depends on specific molecular interactions (Rose et al., 2012). This speciesspecific modulation of the host's immune response by the VMB was also inferred by Doerflinger et al. (2014), who discovered that L. crispatus ATCC 38820 does not significantly up-regulate pattern-recognition receptor (PRR) signaling pathways in human primary vaginal epithelial cells (V19), whereas L. iners ATCC
5195 does. Further, only the studied $L$. iners strain was shown to increase the expression of TNF at RNA level, although an increased secretion of TNF on protein level was not observed (Doerflinger et al., 2014). Whether L. iners is contributing to vaginal health is therefore still controversial. Wagner and Johnson (2012) investigated the influence of L. rhamnosus GR-1 and L. reuteri $\mathrm{RC}-14$ on the inflammatory response of $\mathrm{VK} 2 / \mathrm{E} 6 \mathrm{E} 7$ to $C$. albicans and observed that the probiotic strains modulate the VK2/E6E7 inflammatory immune response to $C$. albicans by suppressing the expression of induced NF- $\kappa \mathrm{B}$ inhibitor kinase

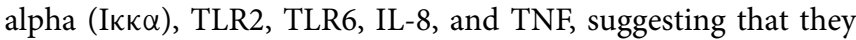
inhibit NF- $\kappa$ B signaling (Wagner and Johnson, 2012). The effect of $L$. rhamnosus GR-1 and L. reuteri RC-14 on the host's immune system was also investigated in vivo (Bisanz et al., 2014). After treatment with these strains, significantly increased levels of IL-5 (as determined by cytokine ELISA assay) and IL-18 (as determined with microarray) could be detected in vaginal swabs, but not for IL-1 $\beta$, TNF, IL-6, and GM-CSF. Furthermore, expression of complement receptors 1 and $3 a$ and TLR2 was significantly increased, suggesting that the lactobacilli have instigated the innate immune system (Bisanz et al., 2014). Nevertheless, more research is needed to substantiate the expression of specific cytokines and immune factors as potential biomarkers of vaginal health.

\section{Probiotics-Exogenously Administered Lactobacillus Strains to Restore Vaginal Health}

Since a healthy VMB is mainly dominated by Lactobacillus species, the perspective of using exogenously applied Lactobacillus probiotics to restore and/or maintain vaginal health becomes feasible. Probiotics are "live microorganisms that, when administered in adequate amounts, confer a health benefit on the host" (FAO/WHO, 2001). Various studies have yet been performed in order to investigate the role of single or a combination of probiotics for the treatment of $\mathrm{BV}$ as the most common vaginal disorder (Table 1) (the main focus of this review). Furthermore, several studies also showed the potential of exogenously administered probiotics for the treatment of another common vaginal disorder, namely candidiasis (Ehrstrom et al., 2010; Vicariotto et al., 2012; De et al., 2014).

\section{Treatment of BV Using Only Probiotic Therapy}

One of the first studies to use probiotic strains for the treatment of BV was conducted in 1992 (Hallen et al., 1992). The authors used vaginal capsules containing $10^{8}-10^{9} \mathrm{CFU}$ of a $\mathrm{H}_{2} \mathrm{O}_{2}$ producing L. acidophilus (Vivag ${ }^{\circledR}$, Pharma-Vinci A/S, Denmark) but did not observe any efficacy for the treatment of BV (as assessed by the Amsel criteria). Nevertheless, it is important to note that $50 \%$ of the patients in the probiotic group and $86 \%$ of the placebo group did not complete the trial, which makes it difficult to evaluate the efficacy of the study. In comparison, by using a $\mathrm{H}_{2} \mathrm{O}_{2}$ producing L. acidophilus, Parent et al. (1996) observed a high BV cure rate of $88 \%$ after 4 weeks of treatment. The authors conducted a placebo-controlled study that included 
TABLE 1 | Use of probiotic strains for the treatment of BV.

\begin{tabular}{lll}
\hline Type of intervention and probiotics used & BV cure rate & Type of study; \\
Duration; & Size & \\
\hline
\end{tabular}

\section{TREATMENT OF BV ONLY WITH PROBIOTICS}

Vaginal capsules containing $10^{8}$ to $10^{9} \mathrm{CFU}^{\star} \mathrm{L}$. acidophilus or placebo for a period of 6 days

Vaginal capsules introduced 1-2 times daily containing at least

$10^{7} \mathrm{~L}$. acidophilus and $0.03 \mathrm{mg}$ estradiol for 6 days
$21 \%$ cure rate compared to $0 \%$ in the control group

\section{$\mathrm{R}, \mathrm{DB}, \mathrm{PC}^{\star *}$ \\ 20-40 days; \\ 57 women}

$88 \%$ cure rate compared to $22 \%$ in the control group

\section{$\mathrm{R}, \mathrm{PC}$;}

4 weeks;
32 women

$65 \%$ cure rate compared to $33 \%$ in the metronidazole treated group

Daily vaginal capsules containing $10^{9} \mathrm{CFU} L$. rhamnosus GRand $10^{9} \mathrm{CFU} L$. reuteri RC-14 or twice a day $0.75 \%$

metronidazole gel for 5 days

Vaginally introduced $1-2$ capsules daily containing at least $10^{9}$ CFU of $L$. brevis CD2, $L$. salivarius FV2 and $L$. plantarum FV9 for a period of 7 days

\section{TREATMENT OF BV WITH PROBIOTICS IN COMBINATION WITH ANTIBIOTIC THERAPY}

Vaginally introduced $100 \mathrm{mg}$ clindamycin ovules for 3 days, subsequently tampons containing $10^{8} \mathrm{CFU}$ of $L$. gasseri, L. casei rhamnosus, $L$. fermentum or placebo tampons during the next menstrual period
As defined by Amsel's criteria 56\% cure rate in the probiotic group and $62 \%$, in the control group; As defined by Nugent's score $55 \%$ cure rate in the probiotic group and $63 \%$, cure in the control group
Oral intake of $500 \mathrm{mg}$ metronidazole for 7 days and oral probiotic capsules containing $L$. rhamnosus GR-1 and $L$. reuteri RC-14 each $10^{9} \mathrm{CFU}$ or placebo for 30 days starting on day 1 of the metronidazole treatment
$88 \%$ cure rate compared to $40 \%$ in the control group

\section{E, OB, AC; \\ 30 days; \\ 40 women \\ Anukam et al. 2006b}

\section{$R, D B, P C$ \\ 3 weeks;}

34 women

Mastromarino et al., 2009

$R, D B, P C$;

Two menstrual periods;

187 women

Eriksson et al., 2005
Oral intake of $300 \mathrm{mg}$ clindamycin for 7 days, followed by vaginal capsules containing $10^{9} \mathrm{CFU}$ L. casei rhamnosus for 7 days
$83 \%$ cure rate compared to $35 \%$ in the control group

$\begin{array}{ll}\mathrm{R}, \mathrm{DB}, \mathrm{PC} ; & \text { Anukam et al., } \\ 30 \text { days; } & 2006 \mathrm{a} \\ 125 \text { women } & \end{array}$

125 women

Vaginal cream containing $2 \%$ clindamycin followed by vaginal capsules containing $10^{8}-10^{9}$ CFU L. gasseri Lba EB01-DSM 14869 and $10^{8}-10^{9}$ L. rhamnosus Lbp PB01-DSM 14870. The probiotic treatment was performed and subsequently repeated for 10 days after each menstruation during 3 menstrual cycles

Treatment with a single dose of tinidazole (2g) plus either 2 oral capsules of $L$. rhamnosus GR-1 and $L$. reuteri RC-14 or placebo daily in the morning for 28 days, starting on the first day
$65 \%$ cure rate compared to $46 \%$ in the control group

$\begin{array}{ll}\text { R, OB, PC; } & \text { Petricevic and Witt, } \\ 4 \text { weeks; } & 2008 \\ 190 \text { women } & \end{array}$

$\mathrm{R}, \mathrm{DB}, \mathrm{PC}$

Larsson et al., 2008 6 menstrual periods; 100 women
Oral $500 \mathrm{mg}$ of metronidazole followed by vaginal application once a week for 6 months of a capsule containing $40 \mathrm{mg}$ of $L$. rhamnosus ( $\mathrm{N} 40000 \mathrm{CFU}$ ) beginning 8 days after the metronidazole therapy
The probiotic group had a significantly higher cure rate of BV (87.5\%) than the placebo group (50.0\%)
$\mathrm{R}, \mathrm{DB}, \mathrm{PC}$; 28 days; 64 women
Martinez et al., 2009

\section{$\mathrm{R}, \mathrm{NB}$;} Marcone et al., 2010

During the first 6 months of follow-up, $96 \%$ of patients in the probiotic group had a balanced vaginal ecosystem. Follow-up over 12 months showed reduced recurrence of $\mathrm{BV}$ in the probiotic group
6 months;

46 women
Oral intake of $400 \mathrm{mg}$ metronidazole for period of 7 days followed by vaginal pessary containing $L$. acidophilus KS400 of $10^{7} \mathrm{CFU}$ and $0.03 \mathrm{mg}$ estriol for 12 days
$72 \%$ cure rate compared to $73 \%$ in the control group

"CFU, colony forming units.

${ }^{* *} R$, randomized; $D B$, double blind; $N B$, not blind; $P C$, placebo controlled; $O B$, observer blind; $A C$, active controlled.

both pregnant and non-pregnant women who were treated with a pharmaceutical product Gynoflor containing at least $10^{7} \mathrm{CFU}$ L. acidophilus and $0.03 \mathrm{mg} / \mathrm{ml}$ estradiol (Parent et al., 1996).
Both studies described above do not use well-characterized probiotic Lactobacillus strains. Even the species designation of these strains could be incorrect, since the group of L. acidophilus has 
been shown to be highly diverse (Falsen et al., 1999). The exact characterization of the probiotic strains used as well as their detailed molecular characterization is mandatory when conducting clinical trials and subsequently delivering a probiotic product to the market. The European Food Safety Authority (EFSA) has stated that an important step toward the approval of health claims for probiotic strains lies in better molecular research followed by multiple well-performed clinical trials. For example, two more recent clinical trials used well-characterized probiotic strains for the treatment of BV (Anukam et al., 2006b; Mastromarino et al., 2009) (Table 1). In the first study, L. rhamnosus GR-1 and L. fermentum RC-14 (now known as L. reuteri RC-14) were vaginally administrated (Anukam et al., 2006b). Both strains are well-known probiotic strains with well documented adhesion capacity to vaginal and uroepithelial cells, as well as capacity to inhibit adhesion and growth of uropathogens (Reid et al., 1987). In addition, $L$. reuteri $\mathrm{RC}-14$ produces biosurfactant compounds (Velraeds et al., 1998) and significant amounts of $\mathrm{H}_{2} \mathrm{O}_{2}$ (Reid et al., 2001). The strains were also successfully recovered from the vaginal niche after oral administration and were shown to persist in the vaginal niche for 19 days post administration (Gardiner et al., 2002). Anukam et al. (2006b) compared the effect of intravaginally introduced capsules of L. rhamnosus GR-1 and L. reuteri RC-14 with metronidazole gel and reported a BV cure rate of $65 \%$ in the probiotic group in comparison to $33 \%$ in the metronidazole treated group (Anukam et al., 2006b). A few follow up studies with HIV patients showed that L. rhamnosus GR-1 and L. reuteri RC-14 were able to reduce episodes of diarrhea, nausea and flatulence (Anukam et al., 2008; Irvine et al., 2010) and to increase the $\mathrm{CD}^{+}$counts in several patients (Hummelen et al., 2011).

In addition to L. rhamnosus GR-1 and L. reuteri $\mathrm{RC}-14$, others also used well-characterized and rationally selected vaginal Lactobacillus strains. For instance, an Italian group investigated capsules containing at least $10^{9} \mathrm{CFU}$ of L. brevis CD2, L. salivarius subsp. salicinius FV2, and L. plantarum FV9 (Mastromarino et al., 2009) after intravaginal introduction using a commercially available product. As described above, the strains were reported to possess anti-pathogenic effect against C. albicans, G. vaginalis, HSV-2, and C. trachomatis (Mastromarino et al., 2002, 2011, 2014; Conti et al., 2009), and were able to colonize the human vagina (Massi et al., 2004). The authors observed that in the probiotic-treated group, the BV cure rate was $50 \%$ compared to only $6 \%$ in the placebo-treated group with the combined diagnostic methods (using Amsel criteria and Nugent scores), whereas a $67 \%$ vs. $12 \%$ cure rate was obtained when considering only the Amsel criteria (Mastromarino et al., 2009).

\section{Treatment of BV Using Probiotic Therapy in Combination with Antibiotic Therapy}

Other studies investigate the role of probiotic treatment following standard antibiotic treatment (Table 1). The first study evaluates the BV cure rate after introducing freeze-dried strains of L. gasseri, L. casei subsp. rhamnosus and L. fermentum impregnated on tampons during menstruation (Eriksson et al., 2005). Each of the women received first clindamycin ovules vaginally once daily for 3 days, followed by probiotic treatment during the next menstruation period. However, the authors did not observe significant BV cure rates after the second menstruation in comparison to the control placebo group. The negative outcome might have multiple reasons, such as the number and the duration of the used tampons, the chosen strains, and the low concentration of Lactobacillus at the end of the study (only $10^{6}$ CFU/ml). Furthermore, as described above, the VMB drastically shifts during menstruation which can be the other possible explanation for the lack of effects observed by Eriksson et al. since the authors administrated the probiotics during menstruation. Anukam et al. (2006a) evaluated the augmentation of antimicrobial metronidazole therapy for BV by a 30 -day oral probiotic treatment using L. rhamnosus GR-1 $\left(10^{9} \mathrm{CFU} / \mathrm{ml}\right)$ and L. reuteri RC-14 $\left(10^{9} \mathrm{CFU} / \mathrm{ml}\right)$. After 30 -day treatment, $88 \%$ of the patients were cured in the antibiotic/probiotic group compared to $40 \%$ in the antibiotic/placebo group. The good record of L. rhamnosus GR-1 and L. reuteri RC-14 was also observed by Martinez et al. (2009) who used vaginal capsules containing the two strains in combination with a single dose of tinidazole $(2 \mathrm{~g})$. The authors observed that the probiotic group had a significantly higher cure rate of $\mathrm{BV}(87.5 \%)$ than the placebo group (50.0\%). Additionally, according to the Nugent score, more women were assessed with normal VMB in the probiotic group (75.0 vs. $34.4 \%$ in the placebo group) (Martinez et al., 2009). Petricevic and Witt (2008) were also able to show restoration of the VMB after antibiotic treatment of BV and exogenously applied L. casei $\mathrm{Lcr} 35\left(10^{9} \mathrm{CFU} / \mathrm{ml}\right)$. Larsson et al. (2008) studied the effect of two probiotic strains introduced vaginally for 10 days during 3 menstrual cycles in a double blind, randomized, placebo-controlled trial. The lactobacilli used were commercially available as EcoVag ${ }^{\circledR}$ vaginal capsules (Bifodan A/S, Denmark) containing L. gasseri (Lba EB01DSM 14869) with a concentration of $10^{8-9}$ CFU/capsule and L. rhamnosus (Lbp PB01-DSM 14870) with a minimal concentration of $10^{8-9} \mathrm{CFU} /$ capsule. The study did not show a positive effect of the supplementary treatment with probiotic lactobacilli during the first month. However, a significantly reduced recurrence rate of $\mathrm{BV}$ at 6 months after the start of the treatment was observed (Larsson et al., 2008). Another more recent study also investigated the effect of probiotic treatment during a period of 6 months (Bradshaw et al., 2012). The authors used $10^{7} \mathrm{CFU} / \mathrm{ml}$ of live L. acidophilus KS400 introduced by a single vaginal pessary for 12 nights, but did not observe reduced BV recurrence. Finally, since L. crispatus species are often isolated from healthy vaginal niches, strains of this species hold great potential as probiotic, such as L. crispatus CTV-05 (LACIN-V), which appears safe in early clinical studies and is able to colonize the vaginal niche (Hemmerling et al., 2009, 2010).

It thus appears that only specific strains and treatment regimens show a beneficial effect of probiotics in BV treatment. Of note, the first conducted systematic review (only based on 4 studies) did not provide conclusive evidence that probiotics can enhance or are better than antibiotics in the treatment of BV (Senok et al., 2009). However, a more recent meta-analysis concluded that probiotics show a beneficial effect in patients who are suffering from BV, based on the included 12 clinical trials (summarized in Table 1) (Huang et al., 2014). One of the advantages of using probiotics unlike antibiotics is the fact that these beneficial bacteria can be used over a long period of time 
without interfering with the normal VMB. Therefore, probiotics cannot only be used for single treatment of BV but also for the prevention of BV recurrence in healthy women with a history of recurrent BV. For example, Ya et al. (2010) evaluated the effect of vaginal probiotic capsules (Probaclac Vaginal; Nicar Laboratories, Inc, Blainville, Quebec, Canada) on BV prophylaxis in healthy women with a history of recurrent BV in a randomized, placebo-controlled, double-blinded study. Between the 2- and 11-month follow up period, women who received probiotics reported lower recurrence rates of $\mathrm{BV}$ and $G$. vaginalis (Ya et al., 2010).

\section{Conclusions}

Several culture-dependent and independent studies highlight the importance of vaginal lactobacilli for a healthy vaginal ecosystem. With the costs of molecular techniques steadily decreasing, it can be anticipated that molecular detection of the presence of lactobacilli at the species or even strain level could gain importance in clinical settings and might form important complementary approaches to the current Nugent and Amsel scoring methods, which could facilitate the use of lactobacilli as a vaginal health biomarker in the clinical setting. Over the last 10 years, NGS techniques have provided a more complete picture of the total bacterial diversity in the vaginal environment. Therefore, the definition of a healthy and normal vaginal microbiota has been re-considered. An emerging number of studies report the presence of non-Lactobacillus dominated VMBs, which potentially corresponds to so called asymptomatic BV, dominated by "BVassociated bacteria". These asymptomatic cases of BV can explain why the treatment of recurrent BV is often unsuccessful. However, the same bacterial species have been also associated with the development of symptomatic BV, although the factors which trigger this condition are largely unknown. It is also questionable whether the "BV-associated bacteria" are really pathogenic and therefore possess pathogenic properties, or whether the host triggers environmental changes which activate different bacterial responses able to develop infection. The definition of a healthy and normal VMB is even more complicated when introducing STIs, which are clearly disease stages. Predisposition for

\section{References}

Allsworth, J. E., Lewis, V. A., and Peipert, J. F. (2008). Viral sexually transmitted infections and bacterial vaginosis: 2001-2004 national health and nutrition examination survey data. Sex. Transm. Dis. 35, 791-796. doi: 10.1097/OLQ.0b013e3181788301

Amsel, R., Totten, P. A., Spiegel, C. A., Chen, K. C., Eschenbach, D., and Holmes, K. K. (1983). Nonspecific vaginitis. Diagnostic criteria and microbial and epidemiologic associations. Am. J. Med. 74, 14-22.

Andersch, B., Forssman, L., Lincoln, K., and Torstensson, P. (1986). Treatment of bacterial vaginosis with an acid cream: a comparison between the effect of lactate-gel and metronidazole. Gynecol. Obstet. Invest. 21, 19-25. doi: $10.1159 / 000298923$

Antonio, M. A., Hawes, S. E., and Hillier, S. L. (1999). The identification of vaginal Lactobacillus species and the demographic and microbiologic many STIs has been directly linked to an unhealthy and abnormal microbiota, although STIs have also been associated with a healthy and normal $\mathrm{VMB}$, suggesting that different types of microbiota might lead to different degrees of predisposition to STIs. Follow up studies are thus strongly required in order to understand the true role of the host and its microbiota in the process of STIs. Therefore, a healthy vaginal microbiota is not merely characterized by the presence of community types, but it is rather characterized by its beneficial function to the host and absence of symptoms, which can be provided by various vaginal types of microbiota, with or without lactobacilli.

Even if lactobacilli are not absolutely required for a healthy $\mathrm{VMB}$, the fact that $70 \%$ of healthy women have a Lactobacillus-dominated microbiota, identified even using NGS techniques, highlights that the targeted and personalized application of Lactobacillus-based vaginal probiotics is still very valid. Successful administration of probiotics to the vaginal niche and treatment of BV will nevertheless depend on the exact Lactobacillus strain(s) used, applied dose, formulation, combination with standard antibiotic treatment, time of administration and duration of the treatment. To determine whether subjects are responders or non-responders to probiotic treatments, specific variables such as race, age of the subjects and dominant VMB might play key roles. Also, large-scale well-designed clinical trials with standardized protocols (consistency regarding species, dosage, route, timing and duration of administration) are of great importance to enable direct comparison between different probiotics.

\section{Acknowledgments}

MP holds a postdoctoral grant from the Fund for Scientific Research (FWO Vlaanderen). Elke Lievens holds a $\mathrm{PhD}$ grant from the Institute for the Promotion of Innovation through Science and Technology in Flanders (IWT Vlaanderen). SM was supported by the KU Leuven (PF 10/18) and Erasmus Mundus. This work was also funded by IOF-SBO funding of the UAntwerpen and FWO KaN funding. We apologize to all colleagues who have not been cited here due to space limitation. characteristics of women colonized by these species. J. Infect. Dis. 180, 1950-1956.

Anukam, K. C., Macklaim, J. M., Gloor, G. B., Reid, G., Boekhorst, J., Renckens, B., et al. (2013). Genome sequence of Lactobacillus pentosus KCA1: vaginal isolate from a healthy premenopausal woman. PLOS ONE 8:e59239. doi: 10.1371/journal.pone.0059239

Anukam, K. C., Osazuwa, E. O., Ahonkhai, I., and Reid, G. (2006c). Lactobacillus vaginal microbiota of women attending a reproductive health care service in Benin city, Nigeria. Sex Transm. Dis. 33, 59-62. doi: 10.1097/01.olq.0000175367.15559.c4

Anukam, K. C., Osazuwa, E. O., Osadolor, H. B., Bruce, A. W., and Reid, G. (2008). Yogurt containing probiotic Lactobacillus rhamnosus GR-1 and L. reuteri RC-14 helps resolve moderate diarrhea and increases CD4 count in HIV/AIDS patients. J. Clin. Gastroenterol. 42, 239-243. doi: 10.1097/MCG.0b013e31802c7465 
Anukam, K. C., Osazuwa, E., Osemene, G. I., Ehigiagbe, F., Bruce, A. W., and Reid, G. (2006b). Clinical study comparing probiotic Lactobacillus GR-1 and RC-14 with metronidazole vaginal gel to treat symptomatic bacterial vaginosis. Microbes. Infect. 8, 2772-2776. doi: 10.1016/j.micinf.2006.08.008

Anukam, K., Osazuwa, E., Ahonkhai, I., Ngwu, M., Osemene, G., Bruce, A. W., et al. (2006a). Augmentation of antimicrobial metronidazole therapy of bacterial vaginosis with oral probiotic Lactobacillus rhamnosus GR-1 and Lactobacillus reuteri $\mathrm{RC}-14$ : randomized, double-blind, placebo controlled trial. Microbes. Infect. 8, 1450-1454. doi: 10.1016/j.micinf.2006.01.003

Atashili, J., Poole, C., Ndumbe, P. M., Adimora, A. A., and Smith, J. S. (2008). Bacterial vaginosis and HIV acquisition: a meta-analysis of published studies. AIDS 22, 1493-1501. doi: 10.1097/QAD.0b013e3283021a37

Atassi, F., Brassart, D., Grob, P., Graf, F., and Servin, A. L. (2006). Lactobacillus strains isolated from the vaginal microbiota of healthy women inhibit Prevotella bivia and Gardnerella vaginalis in coculture and cell culture. FEMS Immunol. Med. Microbiol. 48, 424-432. doi: 10.1111/j.1574-695X.2006. 00162.x

Bisanz, J. E., Seney, S., McMillan, A., Vongsa, R., Koenig, D., Wong, L., et al. (2014). A systems biology approach investigating the effect of probiotics on the vaginal microbiome and host responses in a double blind, placebo-controlled clinical trial of post-menopausal women. PLOS ONE 9:e104511. doi: 10.1371/journal.pone.0104511

Boeke, A. J., Dekker, J. H., van Eijk, J. T., Kostense, P. J., and Bezemer, P. D. (1993). Effect of lactic acid suppositories compared with oral metronidazole and placebo in bacterial vaginosis: a randomised clinical trial. Genitourin. Med. 69, 388-392.

Borgdorff, H., Tsivtsivadze, E., Verhelst, R., Marzorati, M., Jurriaans, S., Ndayisaba, G. F., et al. (2014). Lactobacillus-dominated cervicovaginal microbiota associated with reduced HIV/STI prevalence and genital HIV viral load in African women. ISME J. 8, 1781-1793. doi: 10.1038/ismej.2014.26

Bradshaw, C. S., Pirotta, M., De, G. D., Hocking, J. S., Morton, A. N., Garland, S. M., et al. (2012). Efficacy of oral metronidazole with vaginal clindamycin or vaginal probiotic for bacterial vaginosis: randomised placebo-controlled double-blind trial. PLoS ONE 7:e34540. doi: 10.1371/journal.pone.0034540

Brotman, R. M. (2011). Vaginal microbiome and sexually transmitted infections: an epidemiologic perspective. J. Clin. Invest. 121, 4610-4617. doi: 10.1172/JCI57172

Brotman, R. M., He, X., Gajer, P., Fadrosh, D., Sharma, E., Mongodin, E. F., et al. (2014a). Association between cigarette smoking and the vaginal microbiota: a pilot study. BMC Infect. Dis. 14:471. doi: 10.1186/1471-2334-14-471

Brotman, R. M., Klebanoff, M. A., Nansel, T. R., Andrews, W. W., Schwebke, J. R., Zhang, J., et al. (2008). A longitudinal study of vaginal douching and bacterial vaginosis-a marginal structural modeling analysis. Am. J. Epidemiol. 168, 188-196. doi: 10.1093/aje/kwn103

Brotman, R. M., Klebanoff, M. A., Nansel, T. R., Yu, K. F., Andrews, W. W., Zhang, J., et al. (2010). Bacterial vaginosis assessed by gram stain and diminished colonization resistance to incident gonococcal, chlamydial, and trichomonal genital infection. J. Infect. Dis. 202, 1907-1915. doi: 10.1086/657320

Brotman, R. M., Shardell, M. D., Gajer, P., Tracy, J. K., Zenilman, J. M., Ravel, J., et al. (2014b). Interplay between the temporal dynamics of the vaginal microbiota and human papillomavirus detection. J. Infect. Dis. 210, 1723-1733. doi: 10.1093/infdis/jiu330

Burton, J. P., and Reid, G. (2002). Evaluation of the bacterial vaginal flora of 20 postmenopausal women by direct (Nugent score) and molecular (polymerase chain reaction and denaturing gradient gel electrophoresis) techniques. J. Infect. Dis. 186, 1770-1780. doi: 10.1086/345761

Cardone, A., Zarcone, R., Borrelli, A., Di, C. A., Russo, A., and Tartaglia, E. (2003). Utilisation of hydrogen peroxide in the treatment of recurrent bacterial vaginosis. Minerva Ginecol. 55, 483-492.

Carey, J. C., and Klebanoff, M. A. (2005). Is a change in the vaginal flora associated with an increased risk of preterm birth? Am. J. Obstet. Gynecol. 192, 1341-1346. doi: 10.1016/j.ajog.2004.12.069

Chaban, B., Links, M. G., Jayaprakash, T. P., Wagner, E. C., Bourque, D. K., Lohn, Z., et al. (2014). Characterization of the vaginal microbiota of healthy Canadian women through the menstrual cycle. Microbiome 2:23. doi: 10.1186/20492618-2-23

Chaithongwongwatthana, S., Limpongsanurak, S., and Sitthi-Amorn, C. (2003). Single hydrogen peroxide vaginal douching versus single-dose oral metronidazole for the treatment of bacterial vaginosis: a randomized controlled trial. J. Med. Assoc. Thai. 86(Suppl. 2), S379-S384.

Cherpes, T. L., Hillier, S. L., Meyn, L. A., Busch, J. L., and Krohn, M. A. (2008). A delicate balance: risk factors for acquisition of bacterial vaginosis include sexual activity, absence of hydrogen peroxide-producing lactobacilli, black race, and positive herpes simplex virus type 2 serology. Sex Transm. Dis. 35, 78-83. doi: 10.1097/OLQ.0b013e318156a5d0

Cherpes, T. L., Melan, M. A., Kant, J. A., Cosentino, L. A., Meyn, L. A., and Hillier, S. L. (2005). Genital tract shedding of herpes simplex virus type 2 in women: effects of hormonal contraception, bacterial vaginosis, and vaginal group B Streptococcus colonization. Clin. Infect. Dis. 40, 1422-1428. doi: 10.1086/ 429622

Cherpes, T. L., Meyn, L. A., Krohn, M. A., and Hillier, S. L. (2003a). Risk factors for infection with herpes simplex virus type 2: role of smoking, douching, uncircumcised males, and vaginal flora. Sex Transm. Dis. 30, 405-410. doi: 10.1097/00007435-200305000-00006

Cherpes, T. L., Meyn, L. A., Krohn, M. A., Lurie, J. G., and Hillier, S. L. (2003b). Association between acquisition of herpes simplex virus type 2 in women and bacterial vaginosis. Clin. Infect. Dis. 37, 319-325. doi: 10.1086/375819

Clarke, M. A., Rodriguez, A. C., Gage, J. C., Herrero, R., Hildesheim, A., Wacholder, S., et al. (2012). A large, population-based study of age-related associations between vaginal $\mathrm{pH}$ and human papillomavirus infection. BMC Infect. Dis. 12:33. doi: 10.1186/1471-2334-12-33

Cohen, C. R., Lingappa, J. R., Baeten, J. M., Ngayo, M. O., Spiegel, C. A., Hong, T., et al. (2012). Bacterial vaginosis associated with increased risk of female-tomale HIV-1 transmission: a prospective cohort analysis among African couples. PLoS Med. 9:e1001251. doi: 10.1371/journal.pmed.1001251

Coleman, J. S., Hitti, J., Bukusi, E. A., Mwachari, C., Muliro, A., Nguti, R., et al. (2007). Infectious correlates of HIV-1 shedding in the female upper and lower genital tracts. AIDS 21, 755-759. doi: 10.1097/QAD.0b013e328012b838

Conti, C., Malacrino, C., and Mastromarino, P. (2009). Inhibition of herpes simplex virus type 2 by vaginal lactobacilli. J. Physiol. Pharmacol. 60 (Suppl. 6), 19-26.

Cotter, P. D., Ross, R. P., and Hill, C. (2013). Bacteriocins - a viable alternative to antibiotics? Nat. Rev. Microbiol. 11, 95-105. doi: 10.1038/nrmicro2937

Damelin, L. H., Paximadis, M., Mavri-Damelin, D., Birkhead, M., Lewis, D. A., and Tiemessen, C. T. (2011). Identification of predominant culturable vaginal Lactobacillus species and associated bacteriophages from women with and without vaginal discharge syndrome in South Africa. J. Med. Microbiol. 60, 180-183. doi: 10.1099/jmm.0.024463-0

Datcu, R., Gesink, D., Mulvad, G., Montgomery-Andersen, R., Rink, E., Koch, A., et al. (2013). Vaginal microbiome in women from Greenland assessed by microscopy and quantitative PCR. BMC Infect. Dis. 13:480. doi: 10.1186/14712334-13-480

De, S. F., Parazzini, F., De, L. R., Banco, R., Maso, G. P., De, S. D., et al. (2014). Lactobacillus plantarum P17630 for preventing Candida vaginitis recurrence: a retrospective comparative study. Eur. J. Obstet. Gynecol. Reprod. Biol. 182, 136-139. doi: 10.1016/j.ejogrb.2014.09.018

Doerflinger, S. Y., Throop, A. L., and Herbst-Kralovetz, M. M. (2014). Bacteria in the vaginal microbiome alter the innate immune response and barrier properties of the human vaginal epithelia in a species-specific manner. J. Infect. Dis. 209, 1989-1999. doi: 10.1093/infdis/jiu004

Dols, J. A., Reid, G., Kort, R., Schuren, F. H., Tempelman, H., Bontekoe, T. R., et al. (2012). PCR-based identification of eight Lactobacillus species and $18 \mathrm{hr}-\mathrm{HPV}$ genotypes in fixed cervical samples of South African women at risk of HIV and BV. Diagn. Cytopathol. 40, 472-477. doi: 10.1002/dc.21786

Dominguez-Bello, M. G., Costello, E. K., Contreras, M., Magris, M., Hidalgo, G., Fierer, N., et al. (2010). Delivery mode shapes the acquisition and structure of the initial microbiota across multiple body habitats in newborns. Proc. Natl. Acad. Sci. U.S.A. 107, 11971-11975. doi: 10.1073/pnas.1002601107

Donders, G. G., Van, C. K., Bellen, G., Reybrouck, R., Van den, B. T., Riphagen, I., et al. (2009). Predictive value for preterm birth of abnormal vaginal flora, bacterial vaginosis and aerobic vaginitis during the first trimester of pregnancy. BJOG 116, 1315-1324. doi: 10.1111/j.1471-0528.2009.02237.x

Donia, M. S., Cimermancic, P., Schulze, C. J., Wieland Brown, L. C., Martin, J., Mitreva, M., et al. (2014). A systematic analysis of biosynthetic gene clusters in the human microbiome reveals a common family of antibiotics. Cell 158, 1402-1414. doi: 10.1016/j.cell.2014.08.032 
Drell, T., Lillsaar, T., Tummeleht, L., Simm, J., Aaspollu, A., Vain, E., et al. (2013). Characterization of the vaginal micro- and mycobiome in asymptomatic reproductive-age Estonian women. PLOS ONE 8:e54379. doi: 10.1371/journal.pone.0054379

Eckert, L. O., Moore, D. E., Patton, D. L., Agnew, K. J., and Eschenbach, D. A. (2003). Relationship of vaginal bacteria and inflammation with conception and early pregnancy loss following in-vitro fertilization. Infect. Dis Obstet. Gynecol. 11, 11-17. doi: 10.1155/S1064744903000024

Ehrstrom, S., Daroczy, K., Rylander, E., Samuelsson, C., Johannesson, U., Anzen, B., et al. (2010). Lactic acid bacteria colonization and clinical outcome after probiotic supplementation in conventionally treated bacterial vaginosis and vulvovaginal candidiasis. Microbes. Infect. 12, 691-699. doi: 10.1016/j.micinf.2010.04.010

El Aila, N. A., Tency, I., Claeys, G., Verstraelen, H., Saerens, B., Santiago, G. L., et al. (2009). Identification and genotyping of bacteria from paired vaginal and rectal samples from pregnant women indicates similarity between vaginal and rectal microflora. BMC Infect. Dis. 9:167. doi: 10.1186/1471-2334-9-167

Eriksson, K., Carlsson, B., Forsum, U., and Larsson, P. G. (2005). A double-blind treatment study of bacterial vaginosis with normal vaginal lactobacilli after an open treatment with vaginal clindamycin ovules. Acta. Derm. Venereol. 85, 42-46. doi: 10.1080/00015550410022249

Falsen, E., Pascual, C., Sjoden, B., Ohlen, M., and Collins, M. D. (1999). Phenotypic and phylogenetic characterization of a novel Lactobacillus species from human sources: description of Lactobacillus iners sp. nov. Int. J. Syst. Bacteriol. 49(Pt 1), 217-221. doi: 10.1099/00207713-49-1-217

Ferris, M. J., Norori, J., Zozaya-Hinchliffe, M., and Martin, D. H. (2007). Cultivation-independent analysis of changes in bacterial vaginosis flora following metronidazole treatment. J. Clin. Microbiol. 45, 1016-1018. doi: 10.1128/JCM.02085-06

Forney, L. J., Gajer, P., Williams, C. J., Schneider, G. M., Koenig, S. S., McCulle, S. L., et al. (2010). Comparison of self-collected and physician-collected vaginal swabs for microbiome analysis. J. Clin. Microbiol. 48, 1741-1748. doi: 10.1128/JCM.01710-09

Fredricks, D. N., Fiedler, T. L., and Marrazzo, J. M. (2005). Molecular identification of bacteria associated with bacterial vaginosis. N. Engl. J. Med. 353, 1899-1911. doi: 10.1056/NEJMoa043802

Gajer, P., Brotman, R. M., Bai, G., Sakamoto, J., Schutte, U. M., Zhong, X., et al. (2012). Temporal dynamics of the human vaginal microbiota. Sci. Transl. Med. 4, 132ra52. doi: 10.1126/scitranslmed.3003605

Gallo, M. F., Warner, L., Macaluso, M., Stone, K. M., Brill, I., Fleenor, M. E., et al. (2008). Risk factors for incident herpes simplex type 2 virus infection among women attending a sexually transmitted disease clinic. Sex Transm. Dis. 35, 679-685. doi: 10.1097/OLQ.0b013e31816fcaf8

Gao, W., Weng, J., Gao, Y., and Chen, X. (2013). Comparison of the vaginal microbiota diversity of women with and without human papillomavirus infection: a cross-sectional study. BMC Infect. Dis. 13:271. doi: 10.1186/1471-233413-271

Gardiner, G. E., Heinemann, C., Bruce, A. W., Beuerman, D., and Reid, G. (2002). Persistence of Lactobacillus fermentum RC-14 and Lactobacillus rhamnosus GR-1 but not L. rhamnosus GG in the human vagina as demonstrated by randomly amplified polymorphic DNA. Clin. Diagn. Lab. Immunol. 9, 92-96. doi: 10.1128/CDLI.9.1.92-96.2002

Ghartey, J. P., Smith, B. C., Chen, Z., Buckley, N., Lo, Y., Ratner, A. J., et al. (2014). Lactobacillus crispatus dominant vaginal microbiome is associated with inhibitory activity of female genital tract secretions against Escherichia coli. PLoS ONE 9:e96659. doi: 10.1371/journal.pone.0096659

Gillet, E., Meys, J. F., Verstraelen, H., Bosire, C., De, S. P., Temmerman, M., et al. (2011). Bacterial vaginosis is associated with uterine cervical human papillomavirus infection: a meta-analysis. BMC Infect. Dis. 11:10. doi: 10.1186/14712334-11-10

Gong, Z., Luna, Y., Yu, P., and Fan, H. (2014). Lactobacilli inactivate Chlamydia trachomatis through lactic acid but not $\mathrm{H}_{2} \mathrm{O}_{2}$. PLoS ONE 9:e107758. doi: 10.1371/journal.pone.0107758

Gottlieb, S. L., Douglas, J. M. Jr., Foster, M., Schmid, D. S., Newman, D. R., Baron, A. E., et al. (2004). Incidence of herpes simplex virus type 2 infection in 5 sexually transmitted disease (STD) clinics and the effect of HIV/STD risk-reduction counseling. J. Infect. Dis. 190, 1059-1067. doi: 10.1086/ 423323
Graver, M. A., and Wade, J. J. (2011). The role of acidification in the inhibition of Neisseria gonorrhoeae by vaginal lactobacilli during anaerobic growth. Ann. Clin. Microbiol. Antimicrob. 10:8. doi: 10.1186/1476-0711-10-8

Guise, J. M., Mahon, S., Aickin, M., Helfand, M., Peipert, J., and Westhoff, C. (2001). Screening for bacterial vaginosis in pregnancy. Am. J. Prev. Med. 20, 62-67.

Guo, Y. L., You, K., Qiao, J., Zhao, Y. M., and Geng, L. (2012). Bacterial vaginosis is conducive to the persistence of HPV infection. Int. J. STD AIDS 23, 581-584. doi: 10.1258/ijsa.2012.011342

Gustafsson, R. J., Ahrne, S., Jeppsson, B., Benoni, C., Olsson, C., Stjernquist, M., et al. (2011). The Lactobacillus flora in vagina and rectum of fertile and postmenopausal healthy Swedish women. BMC Womens Health 11, 17-11. doi: 10.1186/1472-6874-11-17

Hallen, A., Jarstrand, C., and Pahlson, C. (1992). Treatment of bacterial vaginosis with lactobacilli. Sex Transm. Dis. 19, 146-148. doi: 10.1097/00007435199205000-00007

Harmanli, O. H., Cheng, G. Y., Nyirjesy, P., Chatwani, A., and Gaughan, J. P. (2000). Urinary tract infections in women with bacterial vaginosis. Obstet. Gynecol. 95, 710-712. doi: 10.1016/S0029-7844(99)00632-8

Hashemi, F. B., Ghassemi, M., Faro, S., Aroutcheva, A., and Spear, G. T. (2000). Induction of human immunodeficiency virus type 1 expression by anaerobes associated with bacterial vaginosis. J. Infect. Dis. 181, 1574-1580. doi: $10.1086 / 315455$

Hellberg, D., Nilsson, S., and Mardh, P. A. (2000). Bacterial vaginosis and smoking. Int. J. STD AIDS 11, 603-606. doi: 10.1258/0956462001916461

Hemmerling, A., Harrison, W., Schroeder, A., Park, J., Korn, A., Shiboski, S., et al. (2009). Phase 1 dose-ranging safety trial of Lactobacillus crispatus CTV05 for the prevention of bacterial vaginosis. Sex Transm. Dis. 36, 564-569. doi: 10.1097/OLQ.0b013e3181a74924

Hemmerling, A., Harrison, W., Schroeder, A., Park, J., Korn, A., Shiboski, S., et al. (2010). Phase 2a study assessing colonization efficiency, safety, and acceptability of Lactobacillus crispatus CTV-05 in women with bacterial vaginosis. Sex Transm. Dis. 37, 745-750. doi: 10.1097/OLQ.0b013e3181e50026

Holst, E., and Brandberg, A. (1990). Treatment of bacterial vaginosis in pregnancy with a lactate gel. Scand. J. Infect. Dis. 22, 625-626. doi: 10.3109/00365549009027109

Huang, H., Song, L., and Zhao, W. (2014). Effects of probiotics for the treatment of bacterial vaginosis in adult women: a meta-analysis of randomized clinical trials. Arch. Gynecol. Obstet. 289, 1225-1234. doi: 10.1007/s00404-0133117-0

Human Microbiome Project Consortium (2012). Structure, function and diversity of the healthy human microbiome. Nature 486, 207-214. doi: 10.1038 /nature 11234

Hummelen, R., Changalucha, J., Butamanya, N. L., Koyama, T. E., Cook, A., Habbema, J. D., et al. (2011). Effect of 25 weeks probiotic supplementation on immune function of HIV patients. Gut. Microbes. 2, 80-85. doi: 10.4161/gmic.2.2.15787

Hummelen, R., Fernandes, A. D., Macklaim, J. M., Dickson, R. J., Changalucha, J., Gloor, G. B., et al. (2010). Deep sequencing of the vaginal microbiota of women with HIV. PLoS ONE 5:e12078. doi: 10.1371/journal.pone.0012078

Irvine, S. L., Hummelen, R., Hekmat, S., Looman, C. W., Habbema, J. D., and Reid, G. (2010). Probiotic yogurt consumption is associated with an increase of CD4 count among people living with HIV/AIDS. J. Clin. Gastroenterol. 44, e201-e205. doi: 10.1097/MCG.0b013e3181d8fba8

Jakobsson, T., and Forsum, U. (2007). Lactobacillus iners: a marker of changes in the vaginal flora? J. Clin. Microbiol. 45, 3145.

Jespers, V., Menten, J., Smet, H., Poradosu, S., Abdellati, S., Verhelst, R., et al. (2012). Quantification of bacterial species of the vaginal microbiome in different groups of women, using nucleic acid amplification tests. BMC Microbiol. 12:83. doi: 10.1186/1471-2180-12-83

Juarez Tomas, M. S., Ocana, V. S., Wiese, B., and Nader-Macias, M. E. (2003). Growth and lactic acid production by vaginal Lactobacillus acidophilus CRL 1259, and inhibition of uropathogenic Escherichia coli. J. Med. Microbiol. 52, 1117-1124. doi: 10.1099/jmm.0.05155-0

Kaul, R., Nagelkerke, N. J., Kimani, J., Ngugi, E., Bwayo, J. J., Macdonald, K. S., et al. (2007). Prevalent herpes simplex virus type 2 infection is associated with altered vaginal flora and an increased susceptibility to multiple sexually transmitted infections. J. Infect. Dis. 196, 1692-1697. doi: 10.1086/522006 
Kaur, B., Balgir, P. P., Mittu, B., Kumar, B., and Garg, N. (2013). Biomedical applications of fermenticin HV6b isolated from Lactobacillus fermentum HV6b MTCC10770. Biomed. Res. Int. 168438. doi: 10.1155/2013/168438

Kilic, A. O., Pavlova, S. I., Alpay, S., Kilic, S. S., and Tao, L. (2001). Comparative study of vaginal Lactobacillus phages isolated from women in the United States and Turkey: prevalence, morphology, host range, and DNA homology. Clin. Diagn. Lab. Immunol. 8, 31-39. doi: 10.1128/CDLI.8.1.31-39.2001

Kiss, H., Kogler, B., Petricevic, L., Sauerzapf, I., Klayraung, S., Domig, K., et al. (2007). Vaginal Lactobacillus microbiota of healthy women in the late first trimester of pregnancy. BJOG 114, 1402-1407. doi: 10.1111/j.14710528.2007.01412.x

Klebanoff, M. A., Schwebke, J. R., Zhang, J., Nansel, T. R., Yu, K. F., and Andrews, W. W. (2004). Vulvovaginal symptoms in women with bacterial vaginosis. Obstet. Gynecol. 104, 267-272. doi: 10.1097/01.AOG.0000134783.98382.b0

Koumans, E. H., Markowitz, L. E., and Hogan, V. (2002). Indications for therapy and treatment recommendations for bacterial vaginosis in nonpregnant and pregnant women: a synthesis of data. Clin. Infect. Dis. 35(Suppl. 2), S152-S172. doi: $10.1086 / 342103$

Lai, S. K., Hida, K., Shukair, S., Wang, Y. Y., Figueiredo, A., Cone, R., et al. (2009). Human immunodeficiency virus type 1 is trapped by acidic but not by neutralized human cervicovaginal mucus. J. Virol. 83, 11196-11200. doi: 10.1128/JVI.01899-08

Lambert, J. A., John, S., Sobel, J. D., and Akins, R. A. (2013). Longitudinal analysis of vaginal microbiome dynamics in women with recurrent bacterial vaginosis: recognition of the conversion process. PLoS ONE 8:e82599. doi: 10.1371/journal.pone.0082599

Larsson, P. G., Stray-Pedersen, B., Ryttig, K. R., and Larsen, S. (2008). Human lactobacilli as supplementation of clindamycin to patients with bacterial vaginosis reduce the recurrence rate; a 6-month, double-blind, randomized, placebocontrolled study. BMC Womens Health 8:3. doi: 10.1186/1472-6874-8-3

Lebeer, S., Vanderleyden, J., and De Keersmaecker, S. C. (2010). Host interactions of probiotic bacterial surface molecules: comparison with commensals and pathogens. Nat. Rev. Microbiol. 8, 171-184. doi: 10.1038/ nrmicro2297

Lee, J. E., Lee, S., Lee, H., Song, Y. M., Lee, K., Han, M. J., et al. (2013). Association of the vaginal microbiota with human papillomavirus infection in a Korean twin cohort. PLOS ONE 8:e63514. doi: 10.1371/journal.pone. 0063514

Looker, K. J., Garnett, G. P., and Schmid, G. P. (2008). An estimate of the global prevalence and incidence of herpes simplex virus type 2 infection. Bull. World Health Organ. 86, 805-812. doi: 10.2471/BLT.07.046128

Low, N., Chersich, M. F., Schmidlin, K., Egger, M., Francis, S. C., van de Wijgert, J. H., et al. (2011). Intravaginal practices, bacterial vaginosis, and HIV infection in women: individual participant data meta-analysis. PLoS Med. 8:e1000416. doi: 10.1371/journal.pmed.1000416

Ma, B., Brotman, R. M., Gajer, P., Fadrosh, D., Mahurkar, A., White, O., et al. (2013a). Association between chlamydia trachomatis genital infection and the vaginal microbiome. Sex Transm. Infect. 89:A35. doi: 10.1136/sextrans-2013051184.0110

Ma, L., Lv, Z., Su, J., Wang, J., Yan, D., Wei, J., et al. (2013b). Consistent condom use increases the colonization of Lactobacillus crispatus in the vagina. PLOS ONE 8:e70716. doi: 10.1371/journal.pone.0070716

Machado, A., Jefferson, K. K., and Cerca, N. (2013). Interactions between Lactobacillus crispatus and Bacterial Vaginosis (BV)-associated bacterial species in initial attachment and biofilm formation. Int. J. Mol. Sci. 14, 12004-12012. doi: $10.3390 /$ ijms 140612004

Macklaim, J. M., Fernandes, A. D., Di Bella, J. M., Hammond, J. A., Reid, G., and Gloor, G. B. (2013). Comparative meta-RNA-seq of the vaginal microbiota and differential expression by Lactobacillus iners in health and dysbiosis. Microbiome 1:12. doi: 10.1186/2049-2618-1-12

Macklaim, J. M., Gloor, G. B., Anukam, K. C., Cribby, S., and Reid, G. (2011). At the crossroads of vaginal health and disease, the genome sequence of Lactobacillus iners AB-1. Proc. Natl. Acad. Sci. U.S.A. 108, 4688-4695. doi: 10.1073/pnas. 1000086107

Malik, S., Siezen, R. J., Renckens, B., Vaneechoutte, M., Vanderleyden, J., and Lebeer, S. (2014). Draft genome sequence of Lactobacillus plantarum CMPG5300, a human vaginal isolate. Genome Announc. 2, e01149-e01114. doi: 10.1128/genomeA.01149-14
Marcone, V., Rocca, G., Lichtner, M., and Calzolari, E. (2010). Long-term vaginal administration of Lactobacillus rhamnosus as a complementary approach to management of bacterial vaginosis. Int. J. Gynaecol. Obstet. 110, 223-226. doi: 10.1016/j.ijgo.2010.04.025

Martin, H. L., Richardson, B. A., Nyange, P. M., Lavreys, L., Hillier, S. L., Chohan, B. et al. (1999). Vaginal lactobacilli, microbial flora, and risk of human immunodeficiency virus type 1 and sexually transmitted disease acquisition. J. Infect. Dis. 180, 1863-1868.

Martin, D. H., Zozaya, M., Lillis, R., Miller, J., and Ferris, M. J. (2012). The microbiota of the human genitourinary tract: trying to see the forest through the trees. Trans. Am. Clin. Climatol. Assoc. 123, 242-256.

Martin, R., Soberon, N., Vaneechoutte, M., Florez, A. B., Vazquez, F., and Suarez, J. E. (2008). Characterization of indigenous vaginal lactobacilli from healthy women as probiotic candidates. Int. Microbiol. 11, 261-266. doi: $10.2436 / 20.1501 .01 .70$

Martin, R., and Suarez, J. E. (2010). Biosynthesis and degradation of $\mathrm{H} 2 \mathrm{O} 2$ by vaginal lactobacilli. Appl. Environ. Microbiol. 76, 400-405. doi: 10.1128/AEM.01631-09

Martinez, R. C., Franceschini, S. A., Patta, M. C., Quintana, S. M., Gomes, B. C., De Martinis, E. C., et al. (2009). Improved cure of bacterial vaginosis with single dose of tinidazole ( $\mathrm{g}$ ), Lactobacillus rhamnosus GR-1, and Lactobacillus reuteri RC-14: a randomized, double-blind, placebo-controlled trial. Can. J. Microbiol. 55, 133-138. doi: 10.1139/W08-102

Martinez, R. C., Franceschini, S. A., Patta, M. C., Quintana, S. M., Nunes, A. C., Moreira, J. L., et al. (2008). Analysis of vaginal lactobacilli from healthy and infected Brazilian women. Appl. Environ. Microbiol. 74, 4539-4542. doi: 10.1128/AEM.00284-08

Martinez-Pena, M. D., Castro-Escarpulli, G., and guilera-Arreola, M. G. (2013). Lactobacillus species isolated from vaginal secretions of healthy and bacterial vaginosis-intermediate Mexican women: a prospective study. BMC Infect. Dis. 13:189. doi: 10.1186/1471-2334-13-189

Masese, L., Baeten, J. M., Richardson, B. A., Bukusi, E., John-Stewart, G., Jaoko, W., et al. (2014). Incident herpes simplex virus type 2 infection increases the risk of subsequent episodes of bacterial vaginosis. J. Infect. Dis. 209, 1023-1027. doi: 10.1093/infdis/jit634

Massi, M., Vitali, B., Federici, F., Matteuzzi, D., and Brigidi, P. (2004). Identification method based on PCR combined with automated ribotyping for tracking probiotic Lactobacillus strains colonizing the human gut and vagina. J. Appl. Microbiol. 96, 777-786. doi: 10.1111/j.1365-2672.2004. 02228.x

Mastromarino, P., Brigidi, P., Macchia, S., Maggi, L., Pirovano, F., Trinchieri, V., et al. (2002). Characterization and selection of vaginal Lactobacillus strains for the preparation of vaginal tablets. J. Appl. Microbiol. 93, 884-893. doi: 10.1046/j.1365-2672.2002.01759.x

Mastromarino, P., Cacciotti, F., Masci, A., and Mosca, L. (2011). Antiviral activity of Lactobacillus brevis towards herpes simplex virus type 2: role of cell wall associated components. Anaerobe 17, 334-336. doi: 10.1016/j.anaerobe.2011.04.022

Mastromarino, P., Di, P. M., Schiavoni, G., Nardis, C., Gentile, M., and Sessa, R. (2014). Effects of vaginal lactobacilli in Chlamydia trachomatis infection. Int. J. Med. Microbiol. 304, 654-661. doi: 10.1016/j.jmm.2014.04.006

Mastromarino, P., Macchia, S., Meggiorini, L., Trinchieri, V., Mosca, L., Perluigi, M., et al. (2009). Effectiveness of Lactobacillus-containing vaginal tablets in the treatment of symptomatic bacterial vaginosis. Clin. Microbiol Infect. 15, 67-74. doi: 10.1111/j.1469-0691.2008.02112.x

McMillan, A., Macklaim, J. M., Burton, J. P., and Reid, G. (2013). Adhesion of Lactobacillus iners AB-1 to Human fibronectin: a key mediator for persistence in the vagina? Reprod. Sci. 20, 791-796. doi: 10.1177/1933719112 466306

Mendes-Soares, H., Suzuki, H., Hickey, R. J., and Forney, L. J. (2014). Comparative functional genomics of Lactobacillus spp. Reveals possible mechanisms for specialization of vaginal lactobacilli to their environment. J. Bacteriol. 196, 1458-1470. doi: 10.1128/JB.01439-13

Minton, K. (2013). HIV: from one STI to another... with love. Nat. Rev. Immunol. 13, 154-155. doi: $10.1038 /$ nri3402

Mitchell, C., Balkus, J. E., Fredricks, D., Liu, C., Kernan-Mullin, J., Frenkel, L. M., et al. (2013). Interaction between lactobacilli, bacterial vaginosis-associated bacteria, and HIV Type 1 RNA and DNA genital shedding in U.S. and 
Kenyan women. AIDS Res. Hum. Retroviruses 29, 13-19. doi: 10.1089/AID. 2012.0187

Nagot, N., Ouedraogo, A., Defer, M. C., Vallo, R., Mayaud, P., and Van de, P. P. (2007). Association between bacterial vaginosis and Herpes simplex virus type2 infection: implications for HIV acquisition studies. Sex Transm. Infect. 83, 365-368. doi: 10.1136/sti.2007.024794

Nardis, C., Mosca, L., and Mastromarino, P. (2013). Vaginal microbiota and viral sexually transmitted diseases. Ann. Ig. 25, 443-456. doi: 10.7416/ai.2013

Nugent, R. P., Krohn, M. A., and Hillier, S. L. (1991). Reliability of diagnosing bacterial vaginosis is improved by a standardized method of gram stain interpretation. J. Clin. Microbiol. 29, 297-301.

Ogawa, Y., Kawamura, T., Matsuzawa, T., Aoki, R., Gee, P., Yamashita, A., et al. (2013). Antimicrobial peptide LL-37 produced by HSV-2-infected keratinocytes enhances HIV infection of Langerhans cells. Cell Host. Microbe. 13, 77-86. doi: 10.1016/j.chom.2012.12.002

O'Hanlon, D. E., Lanier, B. R., Moench, T. R., and Cone, R. A. (2010). Cervicovaginal fluid and semen block the microbicidal activity of hydrogen peroxide produced by vaginal lactobacilli. BMC Infect. Dis. 10:120. doi: 10.1186/14712334-10-120

O'Hanlon, D. E., Moench, T. R., and Cone, R. A. (2011). In vaginal fluid, bacteria associated with bacterial vaginosis can be suppressed with lactic acid but not hydrogen peroxide. BMC Infect. Dis. 11:200. doi: 10.1186/1471-2334-11-200

Ojala, T., Kankainen, M., Castro, J., Cerca, N., Edelman, S., Westerlund-Wikstrom, B., et al. (2014). Comparative genomics of Lactobacillus crispatus suggests novel mechanisms for the competitive exclusion of Gardnerella vaginalis. BMC Genomics 15:1070. doi: 10.1186/1471-2164-15-1070

Osset, J., Bartolome, R. M., Garcia, E., and Andreu, A. (2001). Assessment of the capacity of Lactobacillus to inhibit the growth of uropathogens and block their adhesion to vaginal epithelial cells. J. Infect. Dis. 183, 485-491. doi: $10.1086 / 318070$

Owusu-Edusei, K. Jr., Chesson, H. W., Gift, T. L., Tao, G., Mahajan, R., Ocfemia, M. C., et al. (2013). The estimated direct medical cost of selected sexually transmitted infections in the United States, 2008. Sex Transm. Dis. 40, 197-201. doi: 10.1097/OLQ.0b013e318285c6d2

Parent, D., Bossens, M., Bayot, D., Kirkpatrick, C., Graf, F., Wilkinson, F. E., et al. (1996). Therapy of bacterial vaginosis using exogenously-applied Lactobacilli acidophili and a low dose of estriol: a placebo-controlled multicentric clinical trial. Arzneimittelforschung 46, 68-73.

Pascual, L. M., Daniele, M. B., Giordano, W., Pajaro, M. C., and Barberis, I. L. (2008a). Purification and partial characterization of novel bacteriocin L23 produced by Lactobacillus fermentum L23. Curr. Microbiol. 56, 397-402. doi: 10.1007/s00284-007-9094-4

Pascual, L. M., Daniele, M. B., Ruiz, F., Giordano, W., Pajaro, C., and Barberis, L. (2008b). Lactobacillus rhamnosus L60, a potential probiotic isolated from the human vagina. J. Gen. Appl. Microbiol. 54, 141-148. doi: 10.2323/jgam. 54.141

Petricevic, L., Domig, K. J., Nierscher, F. J., Sandhofer, M. J., Fidesser, M., Krondorfer, I., et al. (2014). Characterisation of the vaginal Lactobacillus microbiota associated with preterm delivery. Sci. Rep. 4:5136. doi: 10.1038/srep05136

Petricevic, L., and Witt, A. (2008). The role of Lactobacillus casei rhamnosus Lcr35 in restoring the normal vaginal flora after antibiotic treatment of bacterial vaginosis. BJOG 115, 1369-1374. doi: 10.1111/j.1471-0528.2008. 01882.x

Petrova, M. I., van den, B. M., Balzarini, J., Vanderleyden, J., and Lebeer, S. (2013). Vaginal microbiota and its role in HIV transmission and infection. FEMS Microbiol Rev. 37, 762-792. doi: 10.1111/1574-6976.12029

Phukan, N., Parsamand, T., Brooks, A. E., Nguyen, T. N., and Simoes-Barbosa, A. (2013). The adherence of Trichomonas vaginalis to host ectocervical cells is influenced by lactobacilli. Sex Transm. Infect. 89, 455-459. doi: 10.1136/sextrans-2013-051039

Rampersaud, R., Planet, P. J., Randis, T. M., Kulkarni, R., Aguilar, J. L., Lehrer, R. I., et al. (2011). Inerolysin, a cholesterol-dependent cytolysin produced by Lactobacillus iners. J. Bacteriol. 193, 1034-1041. doi: 10.1128/JB. 00694-10

Ravel, J., Gajer, P., Abdo, Z., Schneider, G. M., Koenig, S. S., McCulle, S. L., et al. (2011). Vaginal microbiome of reproductive-age women. Proc. Natl. Acad. Sci. U.S.A. 1, 4680-4687. doi: 10.1073/pnas.1002611107
Reid, G., Bruce, A. W., Fraser, N., Heinemann, C., Owen, J., and Henning, B. (2001). Oral probiotics can resolve urogenital infections. FEMS Immunol. Med. Microbiol. 30, 49-52. doi: 10.1111/j.1574-695X.2001. tb01549.x

Reid, G., Cook, R. L., and Bruce, A. W. (1987). Examination of strains of lactobacilli for properties that may influence bacterial interference in the urinary tract. J. Urol. 138, 330-335.

Rizzo, A., Losacco, A., and Carratelli, C. R. (2013). Lactobacillus crispatus modulates epithelial cell defense against Candida albicans through Toll-like receptors 2 and 4, interleukin 8 and human beta-defensins 2 and 3. Immunol. Lett. 156, 102-109. doi: 10.1016/j.imlet.2013.08.013

Ross, S. A., Novak, Z., Ashrith, G., Rivera, L. B., Britt, W. J., Hedges, S. et al. (2005) Association between genital tract cytomegalovirus infection and bacterial vaginosis. J. Infect. Dis. 192, 1727-1730. doi: 10.1086/497150

Rose, W. A., McGowin, C. L., Spagnuolo, R. A., Eaves-Pyles, T. D., Popov, V. L., and Pyles, R. B. (2012). Commensal bacteria modulate innate immune responses of vaginal epithelial cell multilayer cultures. PLoS ONE 7:e32728. doi: 10.1371/journal.pone.0032728

Santiago, G. L., Cools, P., Verstraelen, H., Trog, M., Missine, G., El, A. N., et al. (2011). Longitudinal study of the dynamics of vaginal microflora during two consecutive menstrual cycles. PLOS ONE 6:e28180. doi: 10.1371/journal.pone. 0028180

Santiago, G. L., Tency, I., Verstraelen, H., Verhelst, R., Trog, M., Temmerman, M., et al. (2012). Longitudinal qPCR study of the dynamics of L.crispatus, L. iners, A. vaginae, (sialidase positive) G. vaginalis, and P. bivia in the vagina. PLoS ONE 7:e45281. doi: 10.1371/journal.pone.0045281

Schwebke, J. R., and Desmond, R. (2007). A randomized trial of metronidazole in asymptomatic bacterial vaginosis to prevent the acquisition of sexually transmitted diseases. Am. J. Obstet. Gynecol. 196, 517-516. doi: 10.1016/j.ajog.2007.02.048

Senok, A. C., Verstraelen, H., Temmerman, M., and Botta, G. A. (2009). Probiotics for the treatment of bacterial vaginosis. Cochrane. Database. Syst. Rev 4:CD006289. doi: 10.1002/14651858.CD006289.pub2

Sha, B. E., Zariffard, M. R., Wang, Q. J., Chen, H. Y., Bremer, J., Cohen, M. H., et al. (2005). Female genital-tract HIV load correlates inversely with Lactobacillus species but positively with bacterial vaginosis and Mycoplasma hominis. J. Infect. Dis. 191, 25-32. doi: 10.1086/426394

Shi, Y., Chen, L., Tong, J., and Xu, C. (2009). Preliminary characterization of vaginal microbiota in healthy Chinese women using cultivation-independent methods. J. Obstet. Gynaecol. Res. 35, 525-532. doi: 10.1111/j.14470756.2008.00971.x

Shipitsyna, E., Roos, A., Datcu, R., Hallen, A., Fredlund, H., Jensen, J. S., et al. (2013). Composition of the vaginal microbiota in women of reproductive agesensitive and specific molecular diagnosis of bacterial vaginosis is possible? PLoS ONE 8:e60670. doi: 10.1371/journal.pone.0060670

Shukair, S. A., Allen, S. A., Cianci, G. C., Stieh, D. J., Anderson, M. R., Baig, S. M., et al. (2013). Human cervicovaginal mucus contains an activity that hinders HIV-1 movement. Mucosal. Immunol. 6, 427-434. doi: 10.1038/mi.2012.87

Siezen, R. J., and Kleerebezem, M. (2011). The human gut microbiome: are we our enterotypes? Microb. Biotechnol. 4, 550-553. doi: 10.1111/j.17517915.2011.00290.x

Smith, B. C., McAndrew, T., Chen, Z., Harari, A., Barris, D. M., Viswanathan, S., et al. (2012). The cervical microbiome over 7 years and a comparison of methodologies for its characterization. PLoS ONE 7:e40425. doi: 10.1371/journal.pone.0040425

Spear, G. T., Gilbert, D., Landay, A. L., Zariffard, R., French, A. L., Patel, P., et al. (2011). Pyrosequencing of the genital microbiotas of HIV-seropositive and -seronegative women reveals Lactobacillus iners as the predominant Lactobacillus Species. Appl. Environ. Microbiol. 77, 378-381. doi: 10.1128/AEM. 00973-10

Spear, G. T., Sikaroodi, M., Zariffard, M. R., Landay, A. L., French, A. L., and Gillevet, P. M. (2008). Comparison of the diversity of the vaginal microbiota in HIV-infected and HIV-uninfected women with or without bacterial vaginosis. J. Infect. Dis. 198, 1131-1140. doi: 10.1086/591942

Spurbeck, R. R., and Arvidson, C. G. (2008). Inhibition of Neisseria gonorrhoeae epithelial cell interactions by vaginal Lactobacillus species. Infect. Immun. 76, 3124-3130. doi: 10.1128/IAI.00101-08 
Spurbeck, R. R., and Arvidson, C. G. (2010). Lactobacillus jensenii surfaceassociated proteins inhibit Neisseria gonorrhoeae adherence to epithelial cells. Infect. Immun. 78, 3103-3111. doi: 10.1128/IAI.01200-09

Srinivasan, S., Hoffman, N. G., Morgan, M. T., Matsen, F. A., Fiedler, T. L., Hall, R. W., et al. (2012). Bacterial communities in women with bacterial vaginosis: high resolution phylogenetic analyses reveal relationships of microbiota to clinical criteria. PLoS ONE 7:e37818. doi: 10.1371/journal.pone.0037818

Srinivasan, S., Liu, C., Mitchell, C. M., Fiedler, T. L., Thomas, K. K., Agnew, K. J., et al. (2010). Temporal variability of human vaginal bacteria and relationship with bacterial vaginosis. PLoS ONE 5:e10197. doi: 10.1371/journal.pone.0010197

Strus, M., Brzychczy-Wloch, M., Gosiewski, T., Kochan, P., and Heczko, P. B. (2006). The in vitro effect of hydrogen peroxide on vaginal microbial communities. FEMS Immunol. Med. Microbiol. 48, 56-63. doi: 10.1111/j.1574695X.2006.00120.x

Swidsinski, A., Doerffel, Y., Loening-Baucke, V., Swidsinski, S., Verstraelen, H., Vaneechoutte, M., et al. (2010). Gardnerella biofilm involves females and males and is transmitted sexually. Gynecol. Obstet. Invest. 70, 256-263. doi: $10.1159 / 000314015$

Tamrakar, R., Yamada, T., Furuta, I., Cho, K., Morikawa, M., Yamada, H., et al. (2007). Association between Lactobacillus species and bacterial vaginosisrelated bacteria, and bacterial vaginosis scores in pregnant Japanese women. BMC Infect. Dis. 7:128. doi: 10.1186/1471-2334-7-128

Tanton, C., Weiss, H. A., Le, G. J., Changalucha, J., Rusizoka, M., Baisley, K., et al. (2011). Correlates of HIV-1 genital shedding in Tanzanian women. PLoS ONE 6:e17480. doi: 10.1371/journal.pone.0017480

van de Wijgert, J. H., Borgdorff, H., Verhelst, R., Crucitti, T., Francis, S., Verstraelen, H., et al. (2014). The vaginal microbiota: what have we learned after a decade of molecular characterization? PLOS ONE 9:e105998.

van de Wijgert, J. H., Morrison, C. S., Brown, J., Kwok, C., Van der, P. B., Chipato, T., et al. (2009). Disentangling contributions of reproductive tract infections to HIV acquisition in African Women. Sex Transm. Dis. 36, 357-364. doi: 10.1097/OLQ.0b013e3181a4f695

Vasquez, A., Jakobsson, T., Ahrne, S., Forsum, U., and Molin, G. (2002). Vaginal lactobacillus flora of healthy Swedish women. J. Clin. Microbiol. 40, 2746-2749. doi: 10.1128/JCM.40.8.2746-2749.2002

Velraeds, M. M., van de Belt-Gritter, B., van der Mei, H. C., Reid, G., and Busscher, H. J. (1998). Interference in initial adhesion of uropathogenic bacteria and yeasts to silicone rubber by a Lactobacillus acidophilus biosurfactant. J. Med. Microbiol. 47, 1081-1085.

Verhelst, R., Verstraelen, H., Claeys, G., Verschraegen, G., Delanghe, J., Van, S. L., et al. (2004). Cloning of $16 \mathrm{~S}$ rRNA genes amplified from normal and disturbed vaginal microflora suggests a strong association between Atopobium vaginae, Gardnerella vaginalis and bacterial vaginosis. BMC Microbiol. 4:16. doi: 10.1186/1471-2180-4-16

Verhelst, R., Verstraelen, H., Claeys, G., Verschraegen, G., Van, S. L., De, G. C., et al. (2005). Comparison between Gram stain and culture for the characterization of vaginal microflora: definition of a distinct grade that resembles grade I microflora and revised categorization of grade I microflora. BMC Microbiol. 5:61. doi: 10.1186/1471-2180-5-61

Verhoeven, V., Renard, N., Makar, A., Van, R. P., Bogers, J. P., Lardon, F., et al. (2013). Probiotics enhance the clearance of human papillomavirus-related cervical lesions: a prospective controlled pilot study. Eur. J. Cancer Prev. 22, 46-51. doi: 10.1097/CEJ.0b013e328355ed23

Verstraelen, H., Delanghe, J., Roelens, K., Blot, S., Claeys, G., and Temmerman, M. (2005). Subclinical iron deficiency is a strong predictor of bacterial vaginosis in early pregnancy. BMC Infect. Dis. 5:55. doi: 10.1186/1471-2334-5-55

Verstraelen, H., and Swidsinski, A. (2013). The biofilm in bacterial vaginosis: implications for epidemiology, diagnosis and treatment. Curr. Opin. Infect. Dis. 26, 86-89. doi: 10.1097/QCO.0b013e32835c20cd
Verstraelen, H., Verhelst, R., Claeys, G., Temmerman, M., and Vaneechoutte, M. (2004). Culture-independent analysis of vaginal microflora: the unrecognized association of Atopobium vaginae with bacterial vaginosis. Am. J. Obstet. Gynecol. 191, 1130-1132. doi: 10.1016/j.ajog.2004.04.013

Vicariotto, F., Del, P. M., Mogna, L., and Mogna, G. (2012). Effectiveness of the association of 2 probiotic strains formulated in a slow release vaginal product, in women affected by vulvovaginal candidiasis: a pilot study. J. Clin. Gastroenterol. doi: 10.1097/MCG.0b013e3182684d71

Vielfort, K., Sjolinder, H., Roos, S., Jonsson, H., and Aro, H. (2008). Adherence of clinically isolated lactobacilli to human cervical cells in competition with Neisseria gonorrhoeae. Microbes. Infect. 10, 1325-1334. doi: 10.1016/j.micinf.2008.07.032

Wagner, R. D., and Johnson, S. J. (2012). Probiotic lactobacillus and estrogen effects on vaginal epithelial gene expression responses to Candida albicans. J. Biomed. Sci. 19:58. doi: 10.1186/1423-0127-19-58

Watts, D. H., Fazzari, M., Minkoff, H., Hillier, S. L., Sha, B., Glesby, M., et al. (2005). Effects of bacterial vaginosis and other genital infections on the natural history of human papillomavirus infection in HIV-1-infected and highrisk HIV-1-uninfected women. J. Infect. Dis. 191, 1129-1139. doi: 10.1086/ 427777

Wiesenfeld, H. C., Hillier, S. L., Krohn, M. A., Landers, D. V., and Sweet, R. L. (2003). Bacterial vaginosis is a strong predictor of Neisseria gonorrhoeae and Chlamydia trachomatis infection. Clin. Infect. Dis. 36, 663-668. doi: $10.1086 / 367658$

Witkin, S. S., Mendes-Soares, H., Linhares, I. M., Jayaram, A., Ledger, W. J., and Forney, L. J. (2013). Influence of vaginal bacteria and D- and L-lactic acid isomers on vaginal extracellular matrix metalloproteinase inducer: implications for protection against upper genital tract infections. MBio 4, e00460-e00413. doi: 10.1128/mBio.00460-13

Ya, W., Reifer, C., and Miller, L. E. (2010). Efficacy of vaginal probiotic capsules for recurrent bacterial vaginosis: a double-blind, randomized, placebocontrolled study. Am. J. Obstet. Gynecol. 203, 120-126. doi: 10.1016/j.ajog.2010. 05.023

Zarate, G., and Nader-Macias, M. E. (2006). Influence of probiotic vaginal lactobacilli on in vitro adhesion of urogenital pathogens to vaginal epithelial cells. Lett. Appl. Microbiol. 43, 174-180. doi: 10.1111/j.1472-765X.2006. 01934.x

Zhou, X., Bent, S. J., Schneider, M. G., Davis, C. C., Islam, M. R., and Forney, L. J. (2004). Characterization of vaginal microbial communities in adult healthy women using cultivation-independent methods. Microbiology 150, 2565-2573. doi: 10.1099/mic.0.26905-0

Zhou, X., Hansmann, M. A., Davis, C. C., Suzuki, H., Brown, C. J., Schutte, U., et al. (2010). The vaginal bacterial communities of Japanese women resemble those of women in other racial groups. FEMS Immunol. Med. Microbiol. 58, 169-181. doi: 10.1111/j.1574-695X.2009.00618.x

Zhu, J., Hladik, F., Woodward, A., Klock, A., Peng, T., Johnston, C., et al. (2009). Persistence of HIV-1 receptor-positive cells after HSV-2 reactivation is a potential mechanism for increased HIV-1 acquisition. Nat. Med. 15, 886-892. doi: $10.1038 / \mathrm{nm} .2006$

Conflict of Interest Statement: The authors declare that the research was conducted in the absence of any commercial or financial relationships that could be construed as a potential conflict of interest.

Copyright (C) 2015 Petrova, Lievens, Malik, Imholz and Lebeer. This is an open-access article distributed under the terms of the Creative Commons Attribution License (CC $B Y)$. The use, distribution or reproduction in other forums is permitted, provided the original author(s) or licensor are credited and that the original publication in this journal is cited, in accordance with accepted academic practice. No use, distribution or reproduction is permitted which does not comply with these terms. 